Hydroécol. Appl. (1994) Tome 6 Vol 1-2, pp. 257-292

\title{
Recherches sur l'état physiologique des poissons de la retenue de Pareloup: données relatives à cinq années d'étude
}

\section{Research on the physiological state of fish in Pareloup Reservoir: data from five years of study}

\author{
F. Vellas, J.M. Ferroni, F. Bau et J.P. Parent
}

Laboratoire d'Ecophysiologie des Poissons, Université Paul Sabatier, 38 rue des 36 ponts, 31078 Toulouse Cedex.

Résumé. - L'état physiologique des poissons a été estimé, pour une part, par l'évaluation mensuelle, au cours de quatre années (1984, 1989, 1990, 1991), de caractéristiques morphophysiologiques et de la composition somatique chez deux espèces différant par leur régime alimentaire: la perche et le gardon. Les valeurs obtenues ont démontré qu'il y a certaines années $(1984,1989)$, en été, un ralentissement de la croissance pondérale, une diminution ou un arrêt de l'accrétion protéique accompagné d'une modification de la concentration d'acides aminés ainsi qu'une chute de la teneur en lipides somatiques. Ces résultats indiquent nettement l'existence, dans la retenue de Pareloup, de conditions nutritionnelles plus ou moins favorables aux populations pisciaires, durant la période estivale.

Par ailleurs, la détermination de paramètres sanguins, au cours d'un cycle annuel (19921993), chez plusieurs espèces de poissons (brème, chevesne, brochet, sandre, perche) a révélé que si la valeur de l'hématocrite, la cholestérolémie, la triglycéridémie et la protéinémie sont, d'une manière générale, relativement stables, la glycémie varierait avec la photopériode et le taux d'insuline circulante serait en relation avec le cycle sexuel, pour la plupart des espèces.

Mots-clés. - Poissons, retenue, composition somatique, paramètres sanguins.

Abstract. - The physiological state of fish was first assessed by monthly evaluation in four years $(1984,1989,1990,1991)$ of certain morphophysiological characteristics and of somatic composition in two species (perch and roach) with different dietary habits. In 1984 and 1989, a slowing down in weight gain, a decrease or an interruption in protein accretion associated with changes in amino acid contents, and a fall in somatic lipid levels were observed in summer. These results clearly point to dietary conditions 
in Pareloup Reservoir which are more or less favorable to fish populations during this period.

In addition, blood parameter measurements, carried out from 1992 to 1993 in various fish species (bream, chub, pike, pike-perch, perch), generally showed relatively unchanged values for hematocrit and plasma cholesterol, triglyceride and protein contents, while plasma glucose levels appeared dependent on the photoperiod and circulating insulin rates on the reproductive cycle, for most species.

Key-words. - Fish, reservoir, somatic composition, blood parameters.

\section{INTRODUCTION}

Le poisson, situé en fin de chaîne alimentaire, peut être considéré comme un "intégrateur biologique" de l'évolution de l'écosystème, et la mise en évidence d'altérations de processus physiologiques chez cet animal est susceptible de fournir des renseignements sur le fonctionnement du biotope.

En 1981, une étude hydrobiologique effectuée sur la retenue de $\mathrm{Pa}$ reloup avait révélé une forte tendance eutrophe (Dauba, 1983). En 1984, dans le cadre d'un programme PIREN-Eau, nous nous sommes proposés, en collaboration avec le laboratoire d'Ichtyologie appliquée de l'ENSA Toulouse, d'évaluer l'état nutritionnel de poissons vivant dans ce lac et plus particulièrement des deux espèces les plus représentées numériquement (Dauba, 1983) et différentes par leur régime alimentaire: la perche (Perca fluviatilis L.) carnivore et le gardon (Rutilus rutilus L.) omnivore. En réalité, aucun signe d'eutrophisation n'a été noté cette année-là. Mais, la détermination de caractéristiques morphophysiologiques et biochimiques chez les deux espèces retenues, à quatre périodes de l'année, a indiqué l'existence de conditions environnementales défavorables à leur croissance en été (Parent et al., 1985 ; Caminade, 1986). Or, il est généralement admis que l'époque de croissance des Téléostéens des régions tempérées se situe en saison estivale, et qu'à cette même période, les poissons constituent des réserves corporelles qui seront utilisées durant l'hivernage et la maturation des gonades (Nikolsky, 1963; Newsome et Leduc, 1975; Penczak et al., 1978; Tanasichuk et Mackay, 1989; Karas, 1990); par ailleurs, il a été démontré que les croissances moyennes annuelles des poissons dans le lac de Pareloup sont du même ordre que celles observées dans les eaux douces européennes (Dauba, 1983).

Dans le but d'obtenir des précisions sur l'évolution, au cours des saisons, de l'état physiologique de ces animaux, nous avons alors envisagé de poursuivre notre étude en augmentant la fréquence des prélèvements et ce, pendant plusieurs années consécutives.

Malheureusement, nos travaux ont été arrêtés en 1985, faute d'un support financier suffisant, et ce n'est 
qu'en 1989 qu'ils ont pu être repris en collaboration avec le laboratoire d'Hydrobiologie de l'Université Paul Sabatier.

Cet article est consacré à l'ensemble des recherches que nous avons effectuées sur les variations mensuelles de caractéristiques morphophysiologiques, de la composition somatique et de paramètres sanguins chez des poissons peuplant la retenue de Pareloup.

\section{PRÉLÈVEMENTS DES ÉCHANTILLONS}

Les poissons étaient capturés à l'aide de filets de pêche dont l'utilisation est préconisée lors d'investigations dans les lacs, réservoirs et milieux potamiques (EIFAC, 1975).

Pour suivre l'évolution des caractéristiques morphophysiologiques et de la composition somatique, étude effectuée chez la perche et le gardon, des filets en nylon monofilament de maille de $18 \mathrm{~mm}$ étaient employés; ces filets permettent, tout au long de l'année, une capture sélective nécessaire à ce type de recherche; l'âge et, en conséquence, la taille des poissons peuvent, en effet, fortement influencer les résultats d'analyse corporelle (Elliott, 1976; Craig et al., 1989; Boivin et Power, 1990). Les profondeurs de pêche pouvaient atteindre 10 mètres. Les filets étaient relevés 3 fois par jour $(8-10 \mathrm{~h}, 15$ $17 \mathrm{~h}, \quad 20-21 \mathrm{~h})$. La longueur à la fourche des perches, âgées de 2 à 3 ans, variait de 12 à $16 \mathrm{~cm}$, celle des gardons, âgés de 5 à 6 ans, de 13 à $16 \mathrm{~cm}$.

Pour l'étude des paramètres sanguins qui a été réalisée chez cinq espèces de poissons, les captures d'animaux étaient faites à l'aide de filets de maille de $70 \mathrm{~mm}$ afin de sélectionner des individus de grande taille pour faciliter les prélèvements de sang.

Dans chaque cas, immédiatement après la pêche, les poissons étaient mesurés et les tissus prélevés puis congelés (dans l'azote liquide) en vue des analyses ultérieures.

\section{CARACTÉRISTIQUES MORPHOPHYSIOLOGIQUES CHEZ LA PERCHE ET LE GARDON}

\subsection{Facteur de condition}

Le facteur de condition, indice qui permet de déceler les changements de poids saisonnier indépendamment de la longueur des animaux, est fréquemment utilisé pour évaluer l'état physiologique de populations pisciaires et ce, en terme de réserves nutritionnelles disponibles pour le métabolisme (Caulton et Bursell, 1977).

Cependant, le poids des gonades et du contenu du tube digestif peut influer sur la valeur de ce coefficient (Le Cren, 1951). Aussi, comme on l'a indiqué (Nikolsky, 1963; Lind, 1974), nous avons recherché les variations de "l'embonpoint" des poissons à l'aide du facteur de condition somati- 
que calculé en éliminant du poids total des individus celui des organes génitaux et du tube digestif.

On a rapporté que chez la perche (Le Cren, 1951; Lind, 1974) et chez un Cyprinidé, la vandoise (Penczak et al., 1978), le coefficient somatique s'élève rapidement après la fraie puis diminue en automne et en hiver avec le début de la régénération des gonades et l'arrêt de la croissance. Néanmoins, d'après Le Cren (1951), le même type de variations saisonnières de cet indice est noté chez les poissons immatures. Par ailleurs, seIon Goldspink (1979), chez le gardon, lors des dernières phases de l'élaboration des organes sexuels, soit quand le rapport gonadosomatique est élevé, l'utilisation des réserves somatiques à cette époque est plus marquée chez les femelles que chez les mâles.

Globalement, nos résultats s'accordent avec ces observations puisque pour la perche et le gardon dont la période de reproduction, dans le lac de Pareloup, se situe respectivement en avril-mai et mai-juin, les valeurs du facteur de condition les plus élevées sont notées en juin ou juillet selon les années (fig. 1). En outre, au moment de la maturation des gonades, si nous n'avons pas remarqué de différences entre les animaux reproducteurs et immatures, nous n'avons pu déceler un écart entre les sexes chez les deux espèces.

Les variations saisonnières $\mathrm{du}$ coefficient somatique que nous avons enregistrées au cours des quatre années d'étude ne sont pas, toutefois, similaires, aussi bien chez la perche que chez le gardon. En 1984 et 1989 , on constate que par rapport à ce que l'on observe les deux autres années, la valeur de l'indice de condition est soit plus faible au mois de septembre (perche, 1984 ; gardon, 1984 et 1989) soit diminuée dès le mois de juillet (perche, 1989). Alors que nos premiers essais ne pouvaient le révéler, ces résultats conduisent à reconnaître que, dans la retenue de Pareloup, les conditions environnementales et/ou alimentaires peuvent être, suivant les années, plus ou moins favorables aux populations pisciaires, durant la période estivale. De fait, si les recherches hydrobiologiques effectuées sur ce site n'indiquent pas de variations drastiques des paramètres abiotiques dans l'épilimnion (Salençon et al., 1987-1990), elles démontrent que les biomasses phytoplanctoniques et zooplanctoniques peuvent fortement diminuer en été (Baucheff-Nielsen, 1988; Jrad, 1989; Francisco et Rey, 1994).

Fig. 1. - Facteur de condition chez la perche (a) et le gardon (b); moyenne mensuelle pour chaque année: $\left(100^{*} P-(G+T D)\right) / L^{3}$ ou $P$ : poids de l'animal en $g, G$ : poids des gonades en $g$, TD : poids du tube digestif en $\mathrm{g}$ et $\mathrm{L}$ : longueur standard en $\mathrm{cm}$.

Fig. 1. - Condition lactor in perch (a) and roach (b); average monthly mean for each year: (100 - $P-(G+T D) j / L^{3}$ with $P$ : body weight in $g, G$ : gonad weight in $g$. TD: gut weight in $g$ and $L$ : standard length in $\mathrm{cm}$. 




(b)

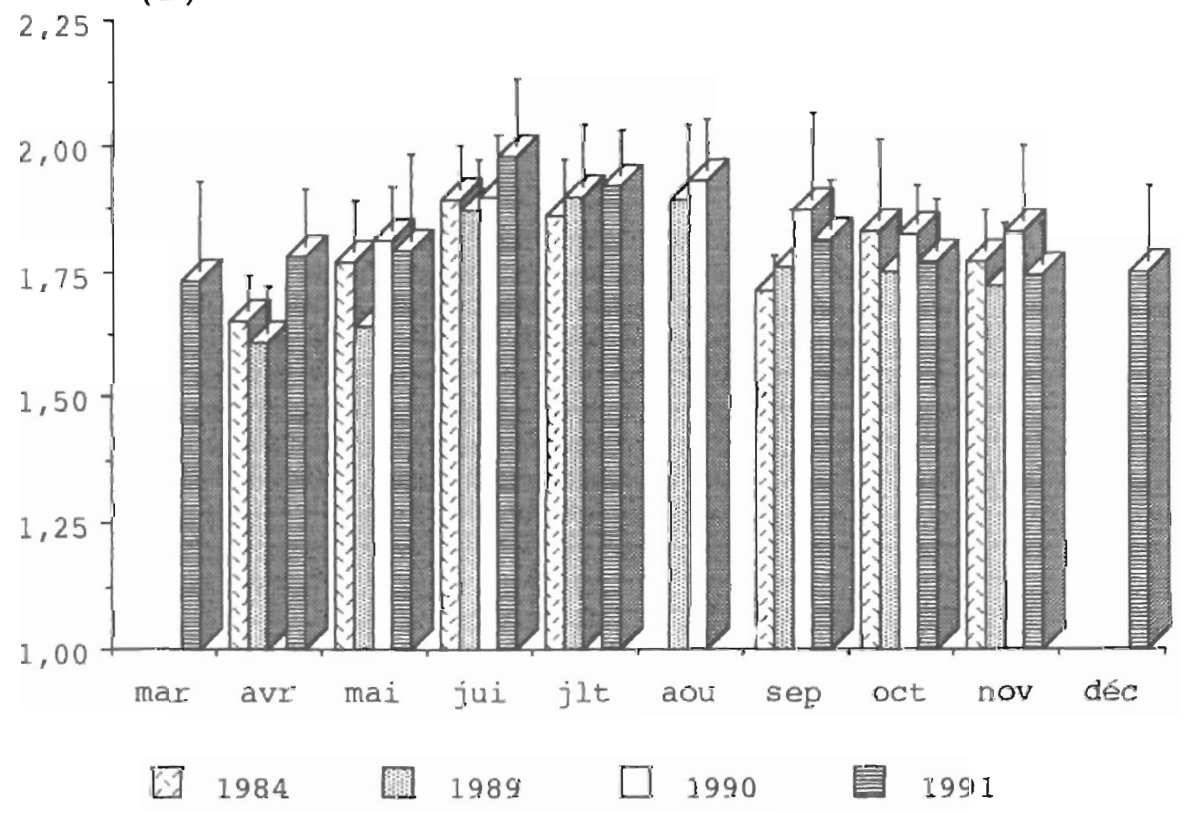




\subsection{Rapport gonadosomatique}

En faisant la synthèse d'un certain nombre d'études, Thorpe (1977) a établi que, chez la perche, les mâles sont à maturité sexuelle durant leur deuxième année de vie et les femelles un ou deux ans plus tard, et que la période de reproduction, à une latitude de 40 à $50^{\circ} \mathrm{N}$, a lieu de mars à la fin mai pour des températures variant de 8 à $11^{\circ} \mathrm{C}$. De plus, Le Cren (1951), Craig (1977), Hokanson (1977) ont rapporté que, chez cette espèce, la régénération des gonades débute fin août et que les organes mâles ont leur poids maximum en octobre-début novembre alors que le développement de l'ovaire est régulier jusqu'à la fraie.

Pour le gardon, poisson chez lequel la maturité sexuelle est atteinte à partir de deux ans pour les femelles et une année plus tôt pour les mâles (Papageorgiou, 1979), divers travaux ont indiqué que la fraie est réalisée à partir du mois d'avril, voire en mai ou juin, selon l'habitat (Goldspink, 1979; Weatherley, 1987; Townsend et Perrow, 1989; Gilet, 1989), la température minimale requise pour la ponte étant de $10^{\circ} \mathrm{C}$ (Papageorgiu, 1979). On a montré, en outre, que, chez cette espèce, l'élaboration des gonades commence en automne pour se poursuivre jusqu'à la période de re- production (Goldspink, 1979; Papageorgiou, 1979).

Nos observations chez les poissons du lac de Pareloup vérifient ces données de la littérature. Chez la perche, âgée de 2 ou 3 ans, seuls les mâles étaient à maturité sexuelle au printemps, et ils ont frayé lorsque la température de l'eau était de 8 à $10^{\circ} \mathrm{C}$; de plus, chez ces individus, le rapport gonadosomatique a toujours été à son maximum en octobre-novembre (fig. 2a). Pour le gardon, âgé de 5 à 6 ans, la ponte a eu lieu quand le niveau thermique de l'eau est passé de 10 à $15^{\circ} \mathrm{C}$, et une reprise de l'activité gonadique a été notée en automne pour les deux sexes (fig. 2b).

\subsection{Rapport hépatosomatique}

Chez les poissons, il y a généralement une corrélation positive entre le poids du foie et le développement des organes sexuels, attribuée à la participation de l'organe hépatique à la synthèse des précurseurs des produits gonadiques; puis, au moment ou juste après la période de reproduction qui est caractérisée par une mobilisation des réserves pour les besoins énergétiques, on observe une perte pondérale du foie; mais, lorsque la fraie est achevée, le plus souvent, le poids de cet organe s'élève (Medford et Mackay, 1978; Dawson et

Fig. 2. - Rapport gonadosomatique; moyenne mensuelle pour l'ensemble des années: (100 * $G /(P-G))$; ind. : gonades indifférenciées. Autres détails comme dans Fig. 1.

Fig. 2. - Gonadosomatic index; average monthly mean for combined years: $(100$ * $G /(P-G))$ : ind.: gonads undifferentiated. Other details as in Fig. 1. 
(a)

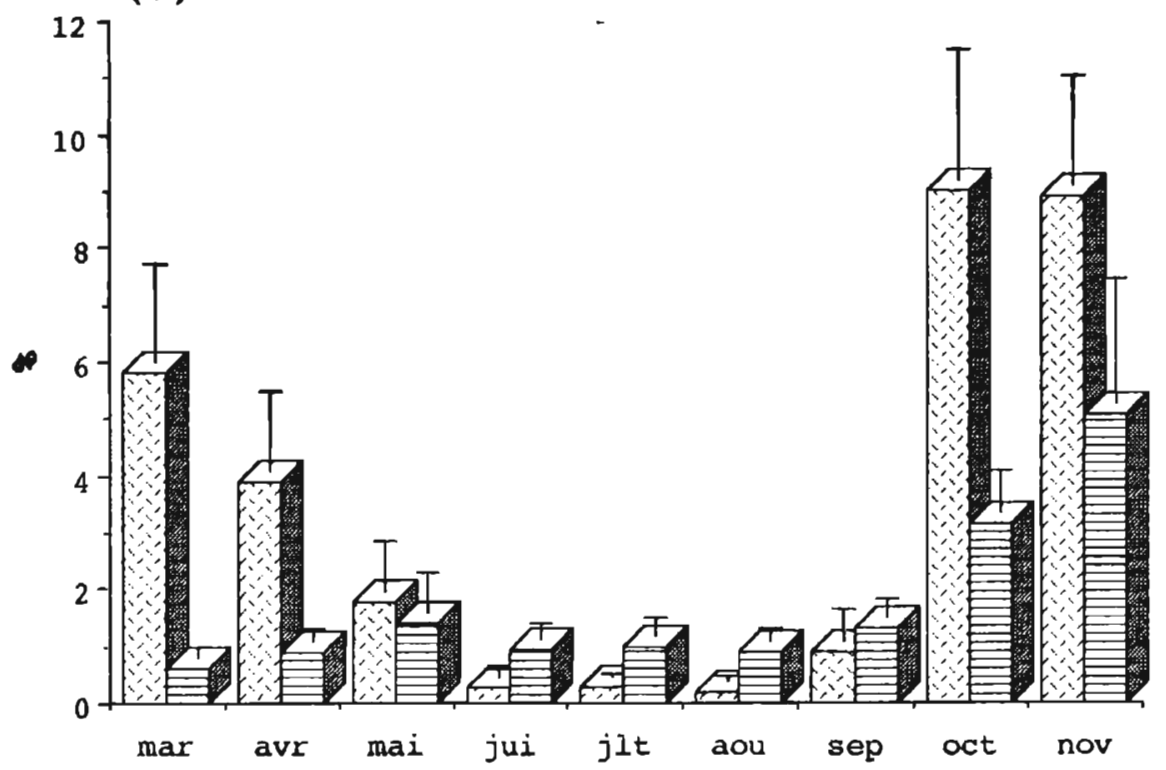

(b)

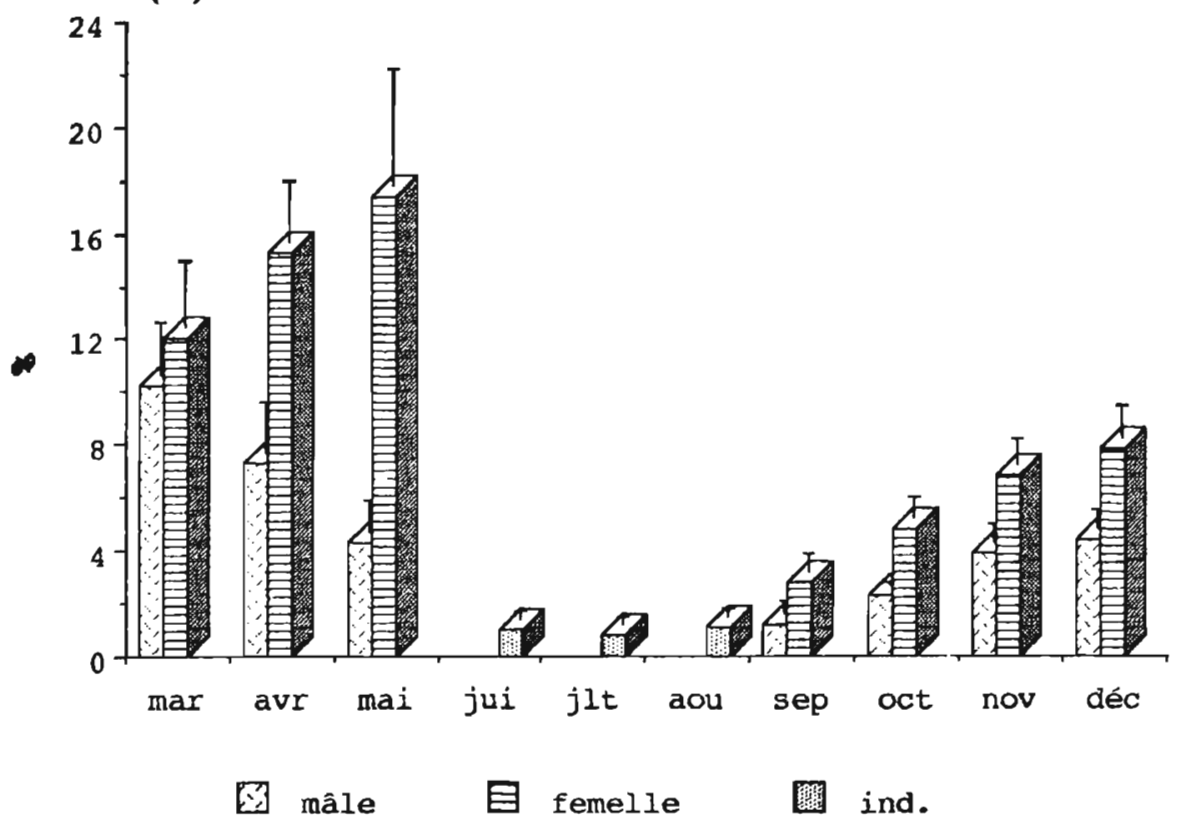


Grimm, 1980; Allen et Wootton, 1982; Overstreet, 1983; Tveranger, 1985; Crupkin et al., 1988). En outre, durant l'élaboration des gonades et/ou, suivant les espèces, pendant la maturation des produits sexuels (Love, 1970; Medford et Mackay, 1978; Overstreet, 1983; Tveranger, 1985), la croissance du foie est plus intense chez les femelles que chez les mâles. Chez la truite arc-en-ciel, Tveranger (1985) a d'ailleurs remarqué que le rapport hépatosomatique chez les mâles est peu différent de celui des individus immatures.

D'après certains travaux, le rapport hépatosomatique varie également, d'une manière sensible et rapide, avec la qualité et la quantité de nourriture ingérée, ce qui a conduit à penser qu'il peut être un bon indicateur de la consommation alimentaire et du stockage d'énergie chez les poissons, en dehors de la période de développement des organes sexuels (Bulow et Coburn, 1976; Heidinger et Crawford, 1977; Miglavs et Jobling, 1989; De Silva et al., 1991; Dos Santos et al., 1993). Mais, la valeur de ce rapport est aussi influencée par la température: une augmentation du niveau thermique entraîne un accroissement de la demande d'énergie qui se traduit, entre autre, par une diminution du poids du foie si les apports nutritionnels sont insuffisants (Heidinger et Crawford, 1977; Bulow et al.,
1978; Jurss, 1979; Parent et Vellas, 1981; Hilton, 1982).

Chez les deux espèces retenues, quelle que soit l'année d'étude, nous avons noté une valeur maximale du rapport hépatosomatique au printemps mais nous n'avons jamais décelé une augmentation de cet indice après la fraie; de plus, en été, il diminue progressivement pour atteindre un minimum en septembre; puis, en automne, il s'accroît avec la régénération des gonades et plus particulièrement chez les femelles (fig. 3). Contrairement à ce que nous avons observé pour le facteur de condition, l'évolution du rapport hépatosomatique chez ces poissons n'apparaît pas ainsi différente suivant les années.

Persson (1987) a remarqué que pour les perches et les gardons d'un lac suédois, les ressources alimentaires du milieu sont limitées en été bien qu'à cette saison les densités de zooplancton soient les plus élevées, ce qu'il a attribué à l'accroissement des besoins métaboliques des poissons induit par l'augmentation thermique.

A Pareloup, il semblerait que l'effet de la température et/ou de tout autre facteur, non seulement en été mais aussi au printemps, soit responsable de la baisse des réserves hépatiques chez la perche et le gardon. Des recherches, réalisées de janvier à juillet

Fig. 3. - Rapport hépatosomatique; moyenne mensuelle pour l'ensemble des années ; $\left(100^{*} H /(P\right.$ $-G)$ ) ; $\mathrm{H}$ : poids du foie en $\mathrm{g}$; ind. : gonades indifférenciées. Autres délails comme dans Fig. 1. Fig. 3. - Liver somatic index; average monthly mean for combined years: $\left(100^{*} \mathrm{H} /(\mathrm{P}-\mathrm{G})\right)$; $\mathrm{H}$ : liver weight in $\mathrm{g}$; ind.: gonads undifferentiated. Other details as in Fig. 1. 

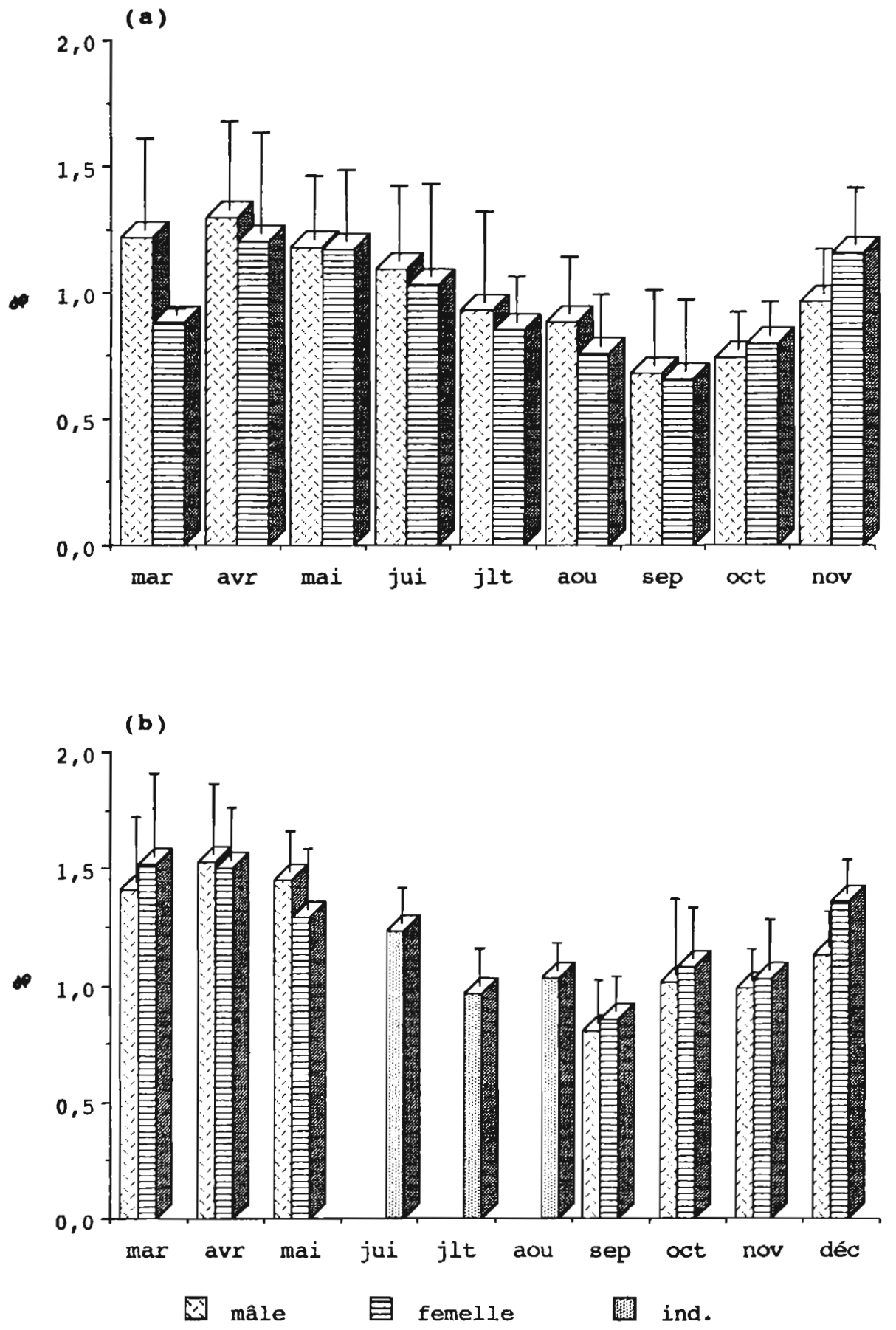
1990, sur le régime alimentaire de ces animaux (Arias-Gonzalez et Richeux, 1990; Richeux et al., 1992) ont nettement démontré que la nourriture consommée par les individus de la même classe d'âge que celle que nous avons choisie est, au printemps et en été, supérieure en qualité et quantité à celle ingérée en hiver.

Enfin, chez les gardons, avant la fraie (mois de mars et d'avril) nous n'avons pas noter une influence du sexe sur le rapport hépatosomatique. Chez les perches, au mois de mars, les valeurs sont plus élevées chez les mâles que chez les femelles immatures. Mais une confirmation de ce dernier résultat est nécessaire puisqu'en fait il ne correspond qu'à un nombre restreint d'échantillons, la capture de poissons au mois de mars n'ayant été effectuée qu'en 1990.

\section{COMPOSITION SOMATIQUE CHEZ LA PERCHE ET LE GARDON}

S'il y a une littérature considérable sur la composition corporelle ou somatique de poissons d'eau douce soumis à des variations de l'environnement contrôlées, les données chez les poissons sauvages sont très limitées. C'est ainsi que dans le cas de la perche, on ne peut citer que les travaux de Craig (1977) sur la perche européenne, de Newsome et Leduc (1975) et de Tanasichuk et Mackay (1989) sur la perchaude, et dans le cas du gardon, seuls les travaux de Penczak et al. (1977) peuvent être mentionnés.

Par ailleurs, dans ces études, la quantité des composants corporels est, le plus souvent, exprimée en pourcentage de poids frais ou de poids sec. Or, Caulton et Bursell (1977) et Dawson et Grimm (1980) ont critiqué, à juste raison, ce mode d'expression car il ne tient pas compte du changement pondéral des animaux et peut conduire à des sur ou sousestimations.

En conséquence, pour éviter de telles erreurs, nous avons exprimé nos résultats en teneurs somatiques. A cet effet, d'après la courbe de croissance de longueur $(\mathrm{Lm})$ établie pour les perches et les gardons de Pareloup (Dauba, 1983), nous avons estimé, lors des prélèvements mensuels, le poids $(\mathrm{Wm})$ des animaux selon l'équation proposé par Dawson et Grimm (1980): $W m=W(L m / L)^{3}$, où $W$ et $L$ sont le poids et la longueur totale du poisson au moment de sa capture. Puis, à partir du poids corporel estimé (Ferroni et al., 1992; Parent et al., 1993) et du rapport gonadosomatique, nous avons évalué le poids du soma.

D'après les recherches effectuées chez la perche et le gardon (Newsome et Leduc, 1975; Craig, 1977; Penczak et al., 1977; Tanasichuk et Mackay, 1989), il y a un fort accroissement des graisses corporelles chez les poissons après la fraie. Nous avons observé le même phénomène puisque, chez les deux espèces, la teneur en lipides du soma augmente 

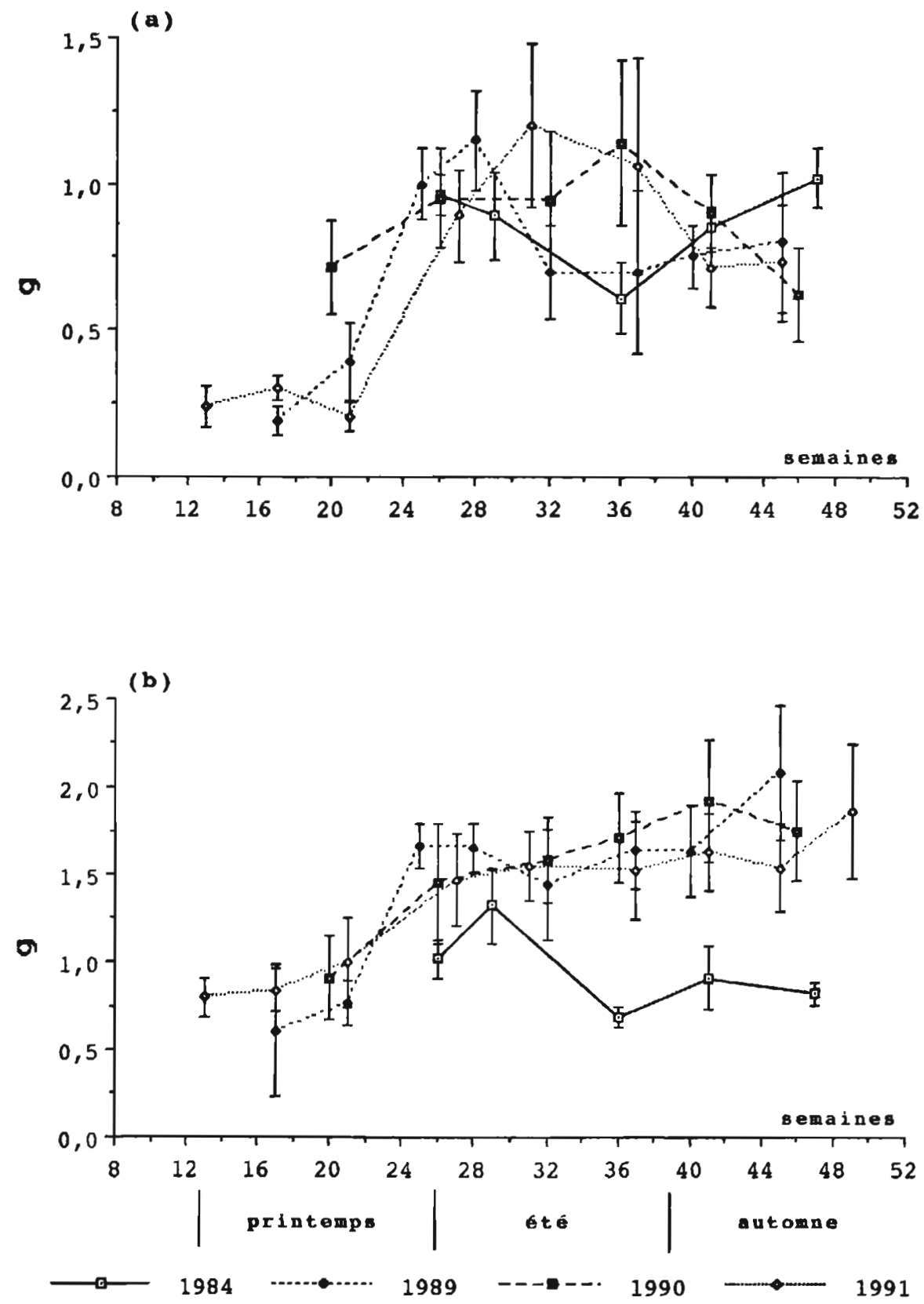

Fig. 4. - Variations saisonnières de la teneur en lipides du soma. Autres détails comme dans Fig. 1.

Fig. 4. - Seasonal changes in somalic lipid contents. Other details as in Fig. 1. 
toujours en mai-juin, c'est-à-dire après la période de reproduction (fig. 4). Mais, durant la période estivale, l'évolution des réserves lipidiques, aussi bien chez la perche que chez le gardon, apparaît différente selon les années considérées (chute plus ou moins précoce en 1984 et en 1989 , augmentation plus ou moins progressive en 1990 et 1991), ce qui est, sans nul doute, en relation avec la quantité d'aliment disponible et vérifie notre hypothèse de l'existence dans la retenue de Pareloup, au cours de cette saison, de conditions nutritionnelles plus ou moins favorables aux populations pisciaires; en effet, l'influence de la ration sur les graisses corporelles a été très souvent soulignée (Gerking, 1955; Brett et al., 1969; Elliott, 1976; Huisman et al., 1979; Weatherley et Gill, 1983; Muje et al., 1989; Storebaken et al., 1991; Hung et al., 1993).

Penczak et al. (1977) ont indiqué que, chez le gardon, les variations saisonnières des teneurs lipidiques sont non seulement liées aux conditions trophiques mais aussi à la reproducion. Tanasichuk et Mackay (1989) ont rapporté que chez la perchaude, les lipides somatiques stockés au cours de l'été sont souvent utilisés dès le début de la régénération des gonades et jusqu'à la période de frai. Les résultats obtenus, en automne, chez la perche (octobre-novembre) ainsi que chez le gardon (novembre) en 1990 et 1991 s'accorderaient avec cette dernière observation. Mais, à cette même saison, les teneurs en lipides du soma tendent à se stabiliser ou augmentent, suivant l'espèce et l'année, en 1984 et 1989, ce qui suggèrerait, comme Eliassen et Vahl (1982) l'ont supposé à la suite de leurs travaux chez la morue, qu'il n'y a qu'une faible participation des processus physiologiques de la reproduction aux variations saisonnières de la composition somatique.

L'arrêt et le ralentissement de l'accrétion protéique et des cendres, notés respectivement chez la perche et le gardon durant les étés 1984 et 1989 (fig. 5 et 6), indiquent également une moindre disponibilité en nourriture à ces moments-là, par rapport aux années 1990 et 1991. Mais, les résultats obtenus en automne, pendant les quatre années d'étude, mettent nettement en évidence qu'il y a au cours de cette saison, en 1984 et 1989, un retour à des conditions adéquates d'alimentation pour les animaux, induisant des compensations métaboliques et des sursauts de croissance (croissance compensatrice ou de récupération) comme on l'a signalé chez les poissons lorsqu'ils trouvent un apport nutritionnel suffisant après une période critique (Bouche et al., 1973; Dobson et Holmes, 1984; Craig, 1985; Black et Love, 1986; Weatherley et Gill, 1987; Miglavs et Jobling, 1989; Jobling et al., 1993). Weiser et al. (1992) et Mendez et Weiser (1993) rapportent d'ailleurs que, chez le gardon juvénile alimenté à satiété après avoir été privé de nourriture, l'intensité des réponses métaboliques et du taux de croissance est positivement corrélée avec la durée du jeûne. L'importance de 

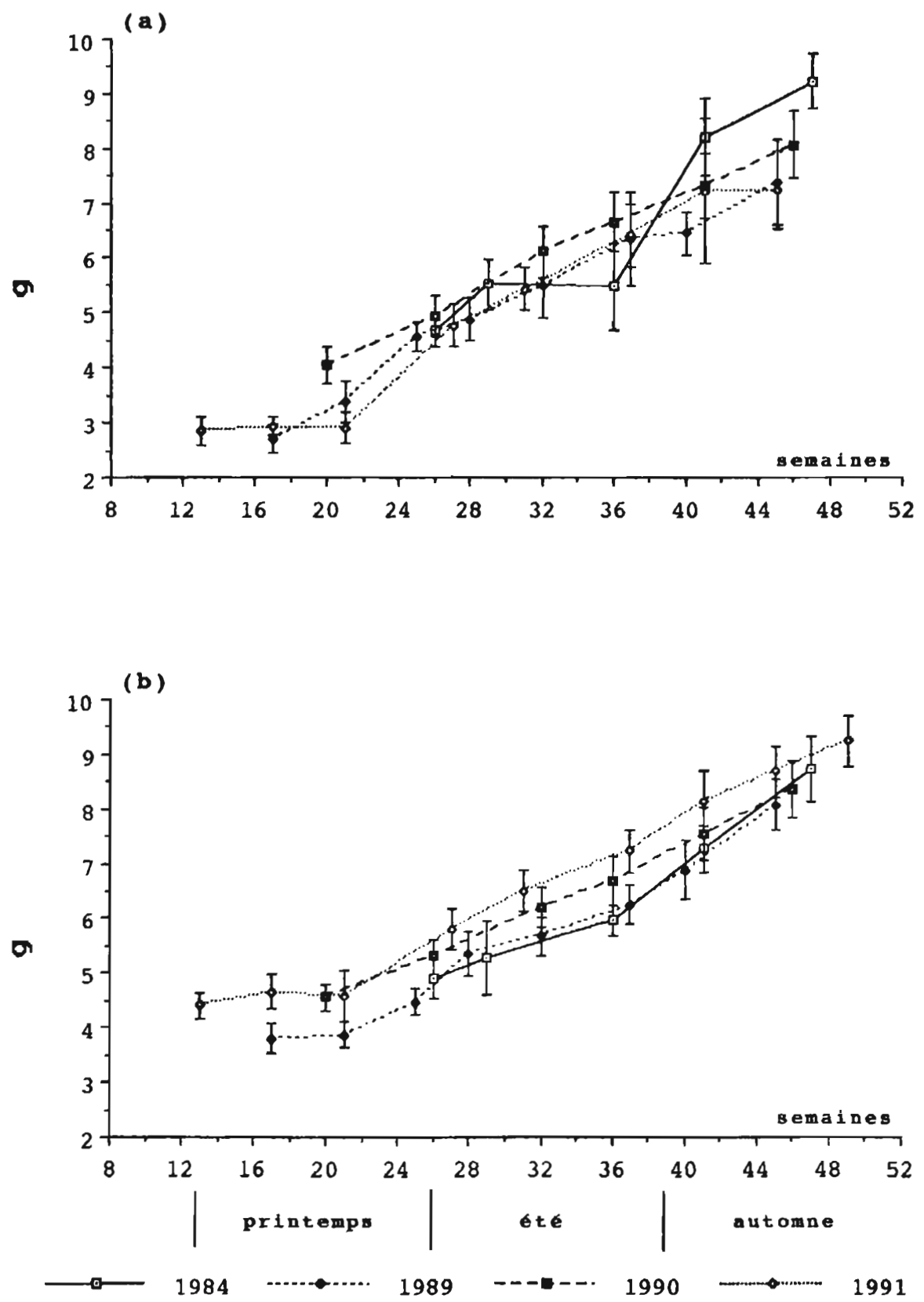

Fig. 5. - Variations saisonnières de la teneur en protéines du soma. Autres détails comme dans Fig. 1.

Fig. 5. - Seasonal changes in somatic protein contents. Other details as in Fig. 1. 

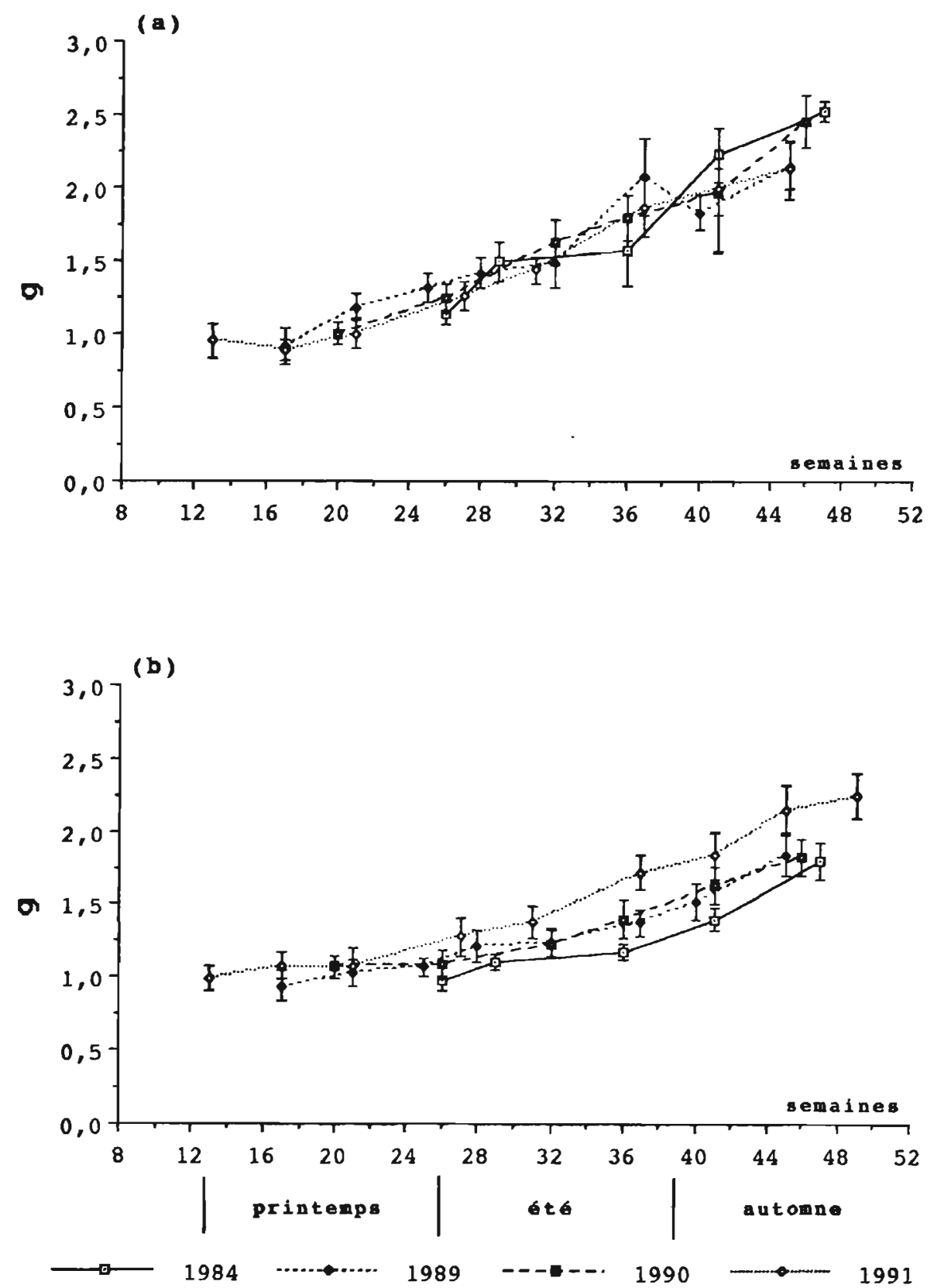

Fig. 6. - Variations saisonnières de la teneur en cendres du soma. Autres détails comme dans Fig. 1.
Fig. 6. - Seasonal changes in somatic ash contents. Other details as in Fig. 1. 
l'accroissement des constituants somatiques remarquée chez la perche, en automne 1984, pourrait ainsi témoigner d'une restriction alimentaire estivale plus sévère pour cette espèce, démontrée, par ailleurs, par la baisse du facteur de condition.

\section{ACIDES AMINÉS DU SOMA CHEZ LA PERCHE ET LE GARDON}

A notre connaissance, il n'y a pas d'études concernant le taux des acides aminés corporels ou somatiques, chez les poissons, en fonction des variations saisonnières de l'environnement. Cependant, on a rapporté qu'il y a des écarts notables dans la concentration de certains de ces composés chez des carpes provenant d'étangs différents (Gheracopol, 1972), et Love (1980) a signalé que la teneur en acides aminés des œufs de poissons est influencée par celle des protéines alimentaires. De plus, on a montré chez la carpe, que le taux des protéines et la valeur énergétique de l'aliment modifient le pourcentage des acides aminés dans la carcasse (Schwartz et Kirchgessner, 1988). Par ailleurs, chez les poissons, une forte corrélation entre les besoins en aminoacides et la teneur en acides aminés de la carcasse a été mise en évidence (Cowey et Tacon, 1983; Wilson et Poe, 1985; Gatlin, 1987), ce qui conduit à admettre que, réciproquement, un déficit de la fraction $\alpha$ aminée alimentaire peut avoir un retentissement sur la composition des protéines corporelles.
Aussi, pour mieux apprécier l'importance des conditions nutritionnelles, en été, pour les poissons du lac de Pareloup, nous nous sommes proposés de déterminer la concentration des aminoacides dans les protéines somatiques de la perche et du gardon, à trois époques de l'année: mois d'avril, mois d'août-septembre, mois de novembre.

A ce jour, les analyses n'ont été effectuées que chez les animaux capturés en 1989 (Parent et al., 1993). Les résultats obtenus (fig. 7 et 8 ) indiquent qu'il y a en été, chez les deux espèces, d'importantes modifications du taux de certains acides aminés, ce qui démontrerait un changement de la qualité des protéines du soma. On observe, en particulier, une baisse des glucoformateurs (principalement du glycocolle et de l'acide glutamique), et l'on peut se demander si elle n'est pas à relier à celle notée dans la fraction $\alpha$-aminée libre du muscle de différentes espèces de poissons lors de l'accroissement des besoins énergétiques provoqué par une élévation de la température (Kaushisk et Luquet, 1979; Knapp et Weiser, 1980, 1981; Parent et al., 1985). On remarque, également, une nette augmentation de l'arginine, de la proline et de la tyrosine aussi bien chez la perche que chez le gardon; mais, dans l'état actuel de nos travaux, il nous est encore difficile d'émettre une hypothèse sur ce phénomène, car si ces animaux subissent les mêmes variations environnementales, ils diffèrent par leur régime alimentaire. 


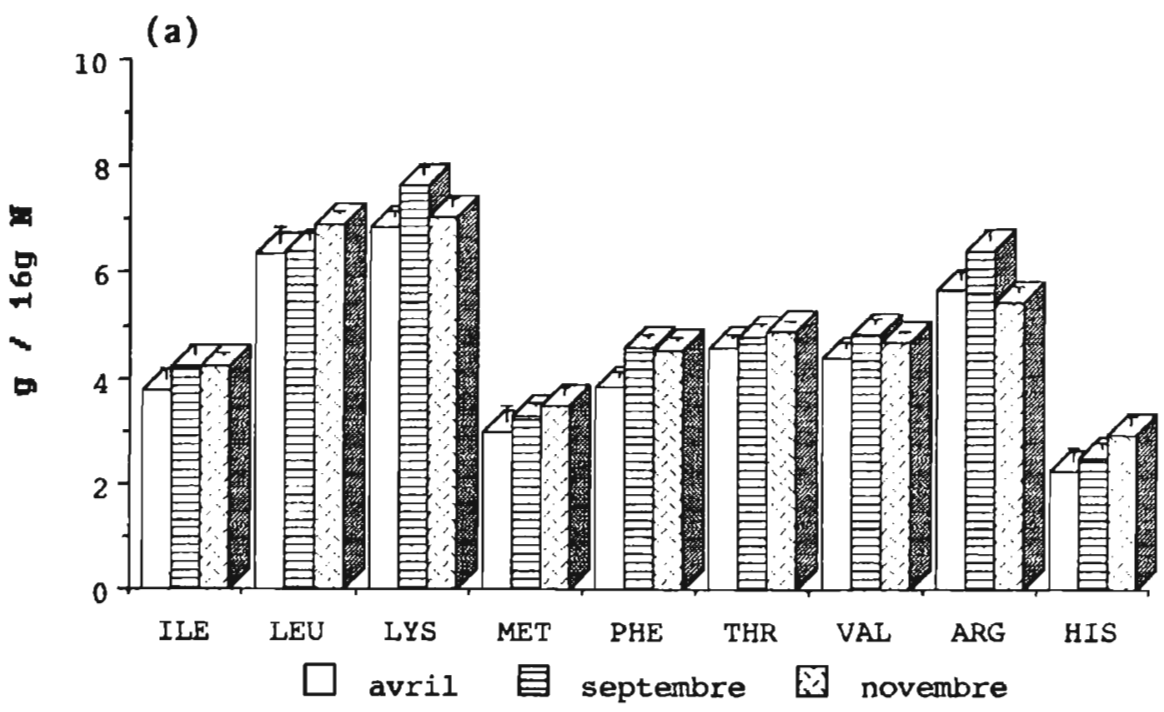

(b)

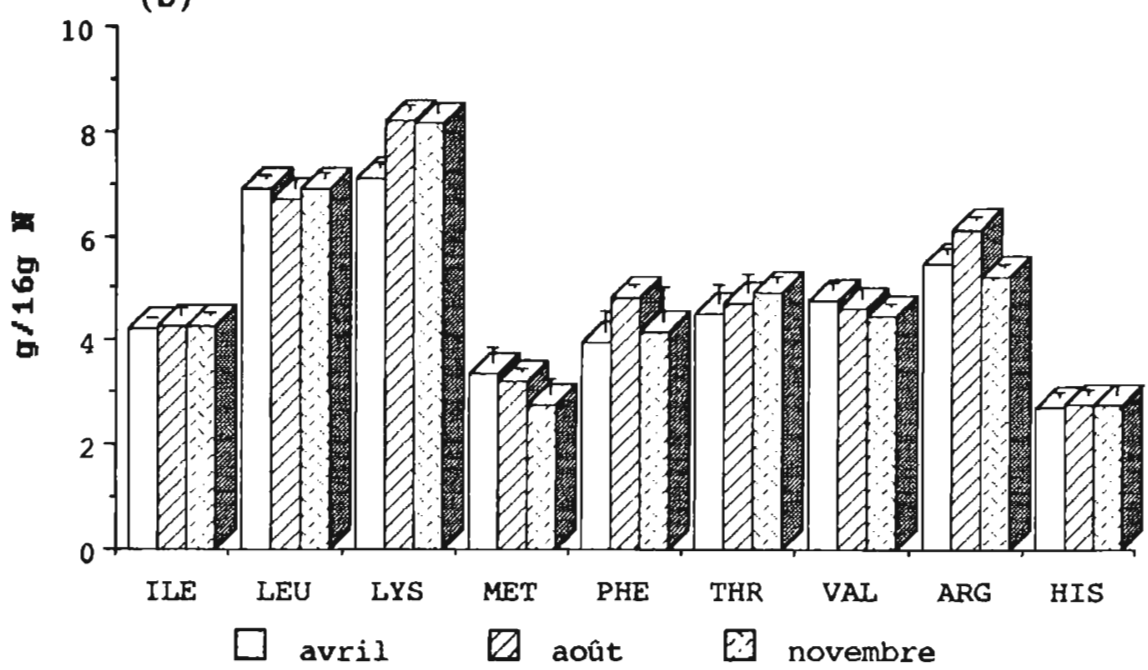

Fig. 7. - Teneurs en acides aminés essentiels du soma. Autres détails comme dans Fig. 1. Fig. 7. - Levels in somatic essential aminoacids. Other details as in Fig. 1. 
(a)

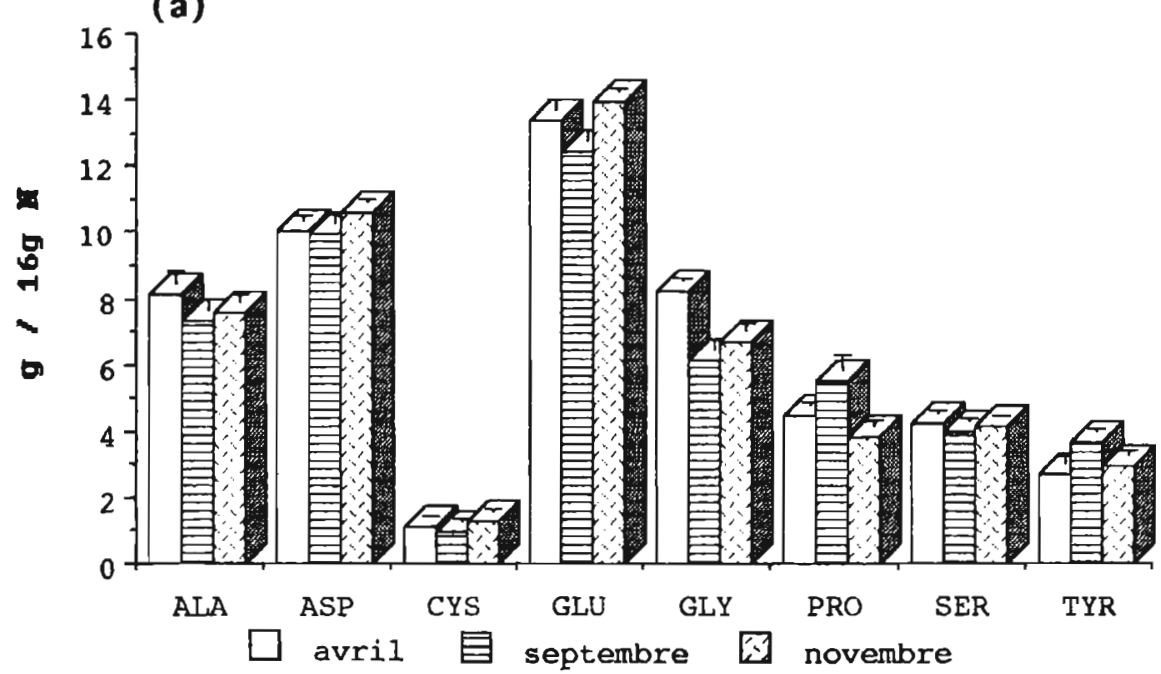

(b)

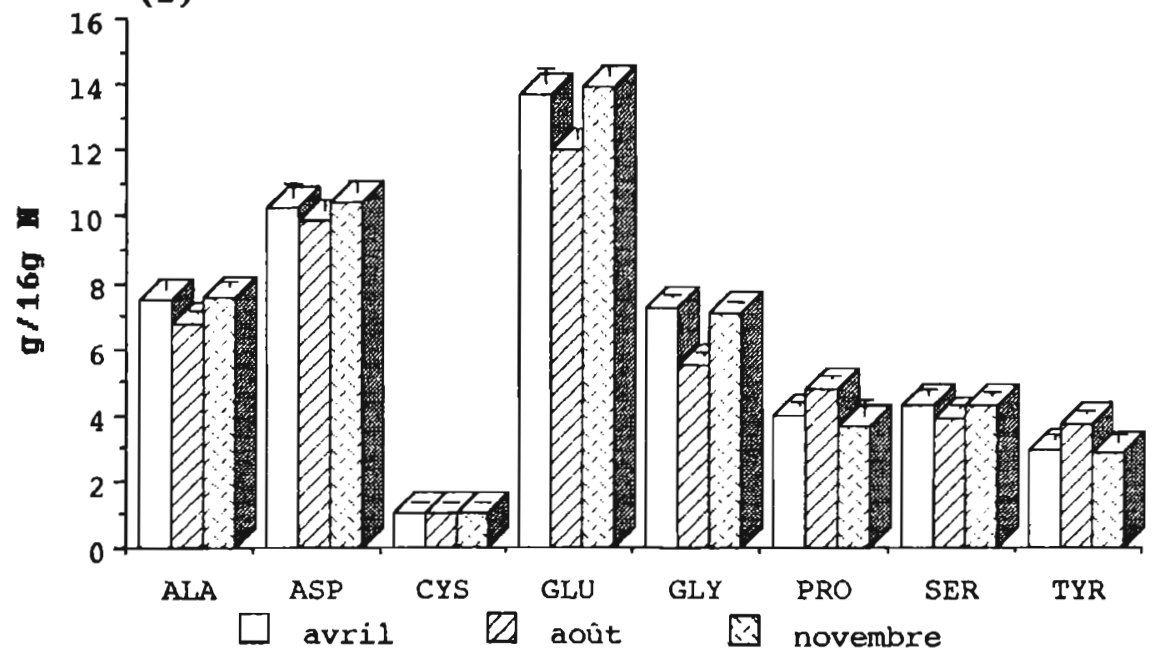

Fig. 8. - Teneurs en acides aminés non essentiels du soma. Autres détails comme dans Fig. 1.

Fig. 8. - Levels in somatic non essential aminoacids. Other details as in Fig. 1. 
5 PARAMĖTRES SANGUINS CHEZ DIVERSES ESPĖCES DE POISSONS

Dans le but d'acquérir des éléments complémentaires à nos recherches précédentes, il nous a paru intéressant de tenter d'établir une "fiche sanitaire" des poissons de la retenue de Pareloup par un suivi, au cours du cycle annuel, des variations de paramètres sanguins chez plusieurs espèces.

Pour cette étude, les animaux ont été capturés d'avril 1992 à mars 1993. Les résultats obtenus actuellement concernent l'hématocrite et les taux plasmatiques de glucose, cholestérol, triglycérides, protéines ainsi que celui d'insuline (hormone pouvant jouer un rôle dans la croissance des animaux) chez trois espèces carnivores : le brochet (Esox lucius L.), le sandre (Stizostedion lucioperca L.), la perche et chez deux espèces omnivores: la brème (Abramis brama L.), le chevesne (Leuciscus cephalus L.) (Bau et al., 1994).

\subsection{Hématocrite}

Chez les poissons, l'hématocrite semble avoir des valeurs relativement constantes qui ne paraissent varier ni en fonction de la température (Parent et al., 1976; Lane, 1979; Sandnes et al., 1988) ou de la photopériode (Lane, 1979; Sandnes et al., 1988) ni en fonction du régime alimentaire, notamment de sa richesse en protéines (Zeitoun et al., 1974; Hemre et al.,
1991; Plisetskaya et al., 1991). Toutefois, des modifications de ce paramètre ont été signalées lors d'un état de stress (Fletcher, 1975; Van Vuren et Hattingh, 1978; Witters et al., 1990; Wells et Weber, 1991). II existe des différences interspécifiques et, globalement, les valeurs rapportées pour ces animaux se situent entre 20 et $50 \%$ (Field et al., 1943; Parent et al., 1976; Perrier et al., 1978b; Schwalme et Mackay, 1985; Miguel et al., 1988; Perez et al., 1989; Hemre et al., 1991).

Les pourcentages d'érythrocytes que nous avons trouvés sont du même ordre de grandeur (fig. 9) et relativement stables pour une espèce donnée. Les valeurs les plus fortes sont notées chez le sandre, mais ce résultat pourrait dépendre de la capture des animaux: le sandre apparaît, effectivement, particulièrement sensible à ce type de capture (il se débat fortement dans le filet une fois capturé, puis montre des difficultés à ventiler) et la phase d'hypoxie ou même d'asphyxie à laquelle il est soumis pourrait provoquer une augmentation de l'hématocrite (Randall, 1982; Pearson et Stevens, 1991; Wells et Weber, 1991).

\subsection{Glycémie}

Les valeurs de glycémie obtenues (fig. 10) sont généralement supérieures à celles indiquées dans la littérature pour différentes espèces $(0,5$ à $1 \mathrm{~g} / \mathrm{l}$ de plasma) (Field et al., 1943; Wedemeyer et Chatterton, 1970; Perrier ef al., 1978a; Parent et al., 1981; 

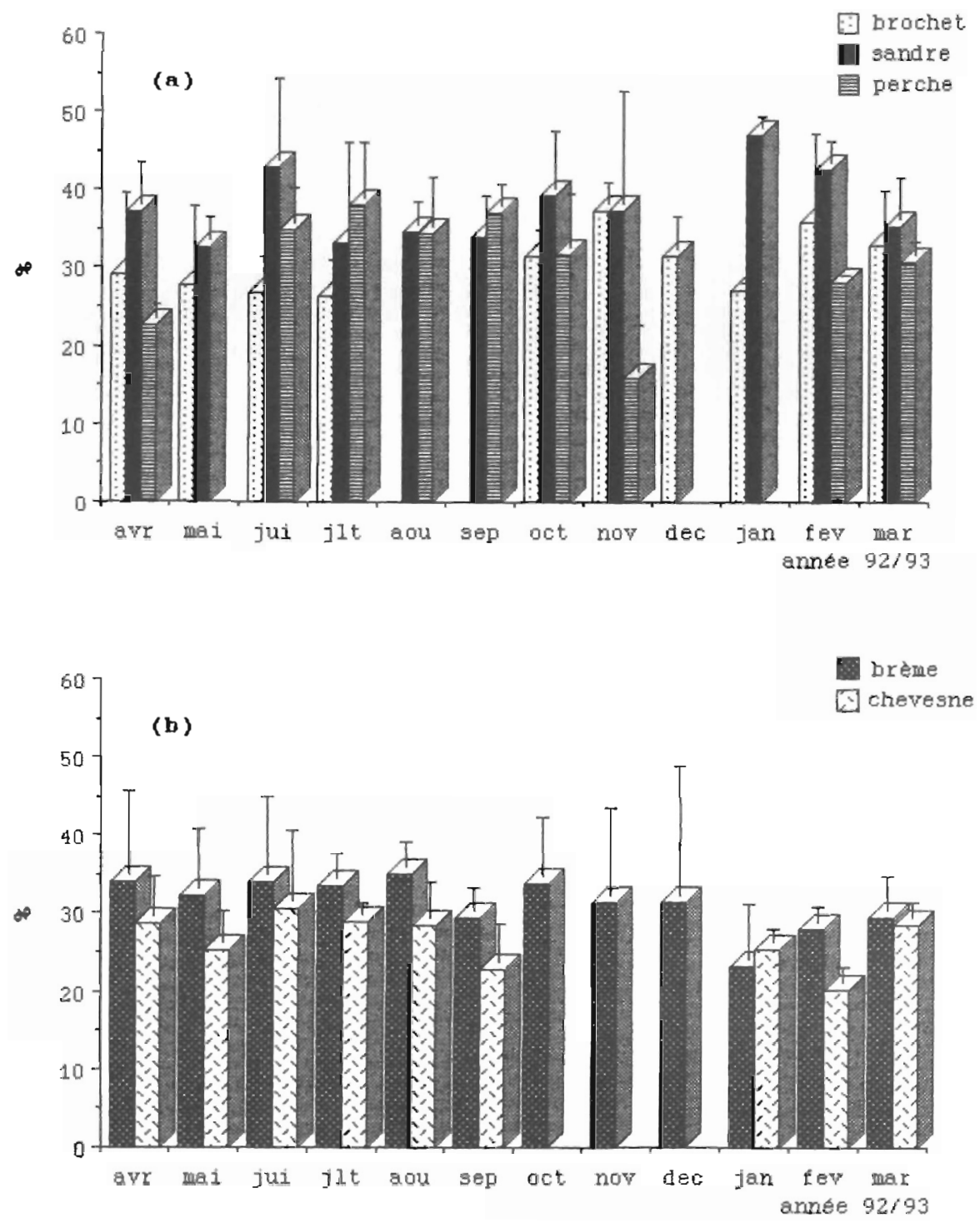

Fig. 9. - Variations mensuelles de l'hématocrite chez les carnivores (a) et les omnivores (b).

Fig. 9. - Monthly changes in hematocrit in carnivorous species (a) and omnivorous species (b).

Schwalme et Mackay, 1985; Witters et al., 1990). Le stress, que les animaux subissent par la pêche au filet et pendant le prélèvement sanguin, est certainement responsable de cette hyperglycémie. De nombreux travaux ont démontré que le taux de glucose plasmatique est positivement corrélé 

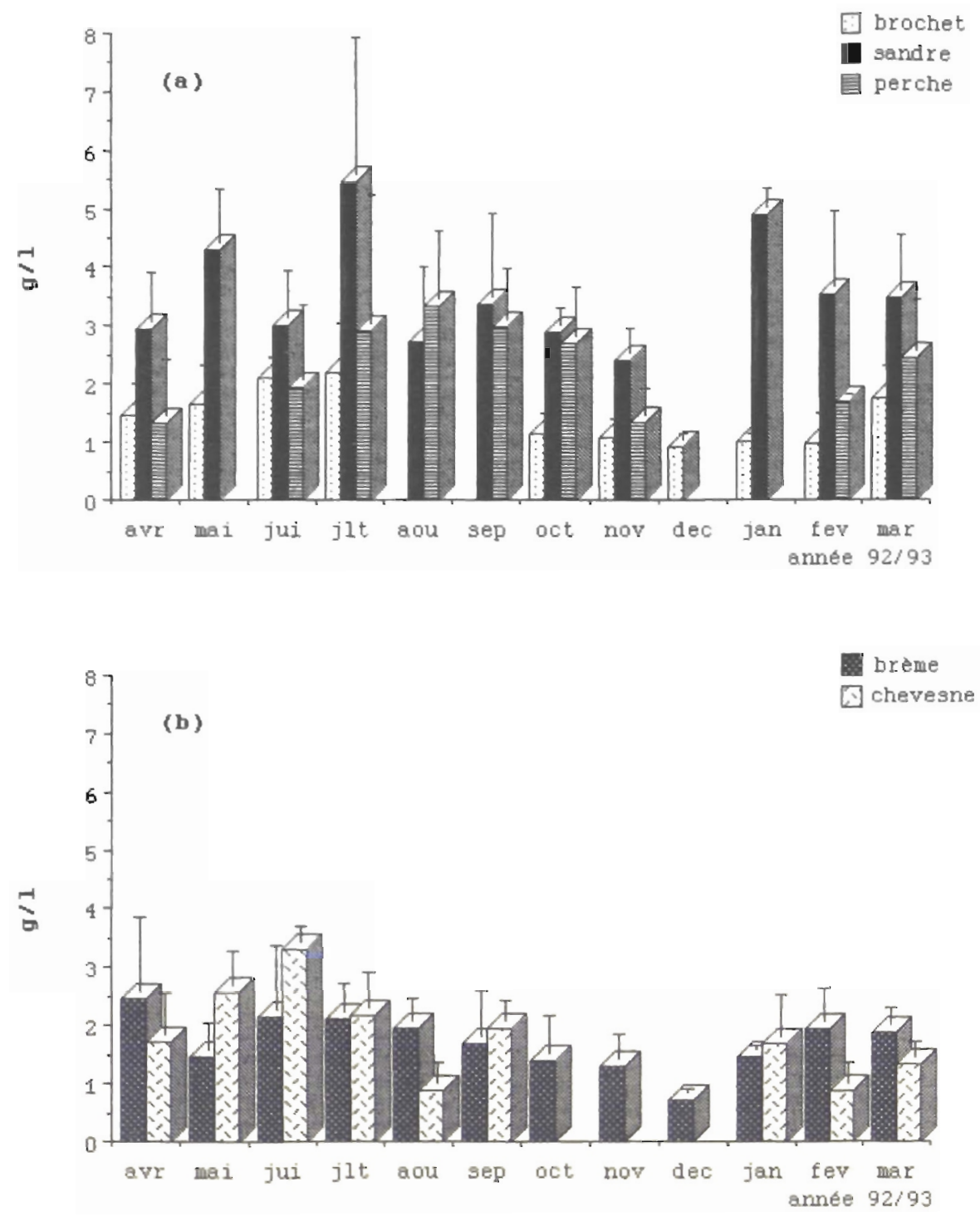

Fig. 10. - Variations mensuelles de la glycémie. Autres détails comme dans Fig. 9. Fig. 10. - Monthly changes in plasma glucose levels. Other details as in Fig. 9.

avec le stress de la capture et de la manipulation (Perrier et al., 1971, 1978b, 1979; Ince et Thorpe, 1975; Casillas et Smith, 1977; Schwalme et
Mackay, 1985, 1990; Hemre et al., 1991). Toutefois, au cours du cycle annuel, la glycémie apparaît la plus élevée chez les Percidés ce qui pour- 
rait résulter de leur activité physique (Leibson et Plisetskaya, 1968; Patent, 1970; Schwalme et Mackay, 1990). A l'inverse des trois autres espèces, la perche est un chasseur actif dans la recherche de sa nourriture et le sandre, un prédateur de poursuite (Popova et Sytina, 1977; Chappaz et al., 1989).

D'après certains travaux, les variations saisonnières de la glycémie, chez les poissons, seraient en étroite relation avec la période de reproduction et l'alimentation (Gutierrez et al., 1987, 1988). Mais, selon Sweeting et al. (1985) et Perez et al. (1988), elles seraient dues à la photopériode. Nos résultats pourraient confirmer cette dernière hypothèse puisque d'une façon générale, chez toutes les espèces, le taux de glucose sanguin paraît atteindre un maximum au début de la période estivale, soit au solstice d'été, et un minimum en novembredécembre, soit au solstice d'hiver. Cependant, l'augmentation plus ou moins précoce selon l'espèce, observée durant la période hivernale, peut être en relation avec les basses températures $\left(4,8^{\circ} \mathrm{C}\right.$ en janvier, $2^{\circ} \mathrm{C}$ en mars) (Love, 1970, 1980; Smit et al., 1981).

\subsection{Cholestérolémie}

Les taux plasmatiques de cholestérol sont importants chez les poissons (Frémont et Léger, 1981) et sont compris, en général, entre 1 et $4 \mathrm{~g} / \mathrm{l}$. II y a des différences entre espèces (Wedemeyer et Chatterton, 1970; Sandnes et al., 1988; Leamaster et al., 1990) et au sein d'une même espèce (Barnhart, 1969).

Nos résultats (fig. 11) paraissent s'accorder avec ces données. On remarque, en particulier, une stabilité quasi annuelle de la cholestérolémie chez la brème, le chevesne et le brochet alors que, chez la perche, les taux de cholestérol sont élevés durant les mois les plus chauds, de juin à octobre (la température de l'eau étant supérieure à $15^{\circ} \mathrm{C}$ ), et, chez le sandre, seule une baisse significative est enregistrée en novembre. En outre, les plus fortes valeurs sont notées chez les Percidés.

Comme l'ont indiqué de nombreux auteurs (Barnhart, 1969; Frémont et Léger, 1981; Kaushik et Luquet, 1979; Shimma et al., 1982; Alexis et al., 1986; Lemaire et al., 1991), l'alimentation pourrait être impliquée dans la variation de ce paramètre. Néanmoins, il est difficile d'expliquer les écarts observés entre le brochet et les Percidés qui ont un régime alimentaire semblable. D'ailleurs, alors que, chez des poissons en élevage (Salmonidés et carassin), une relation inverse entre le niveau thermique de l'eau et le taux de cholestérol plasmatique a été décelée (Hille, 1982; Delahunty et De Vlaming, 1980; Sandnes et al., 1988), chez la perche, il semblerait qu'une température supérieure à $15^{\circ} \mathrm{C}$ soit responsable des valeurs élevées de la cholestérolémie. Une vérification de cette hypothèse est toutefois nécessaire.

L'influence de la photopériode sur ce parametre sanguin (Delahunty et al., 1978; Delahunty et De Vlaming, 

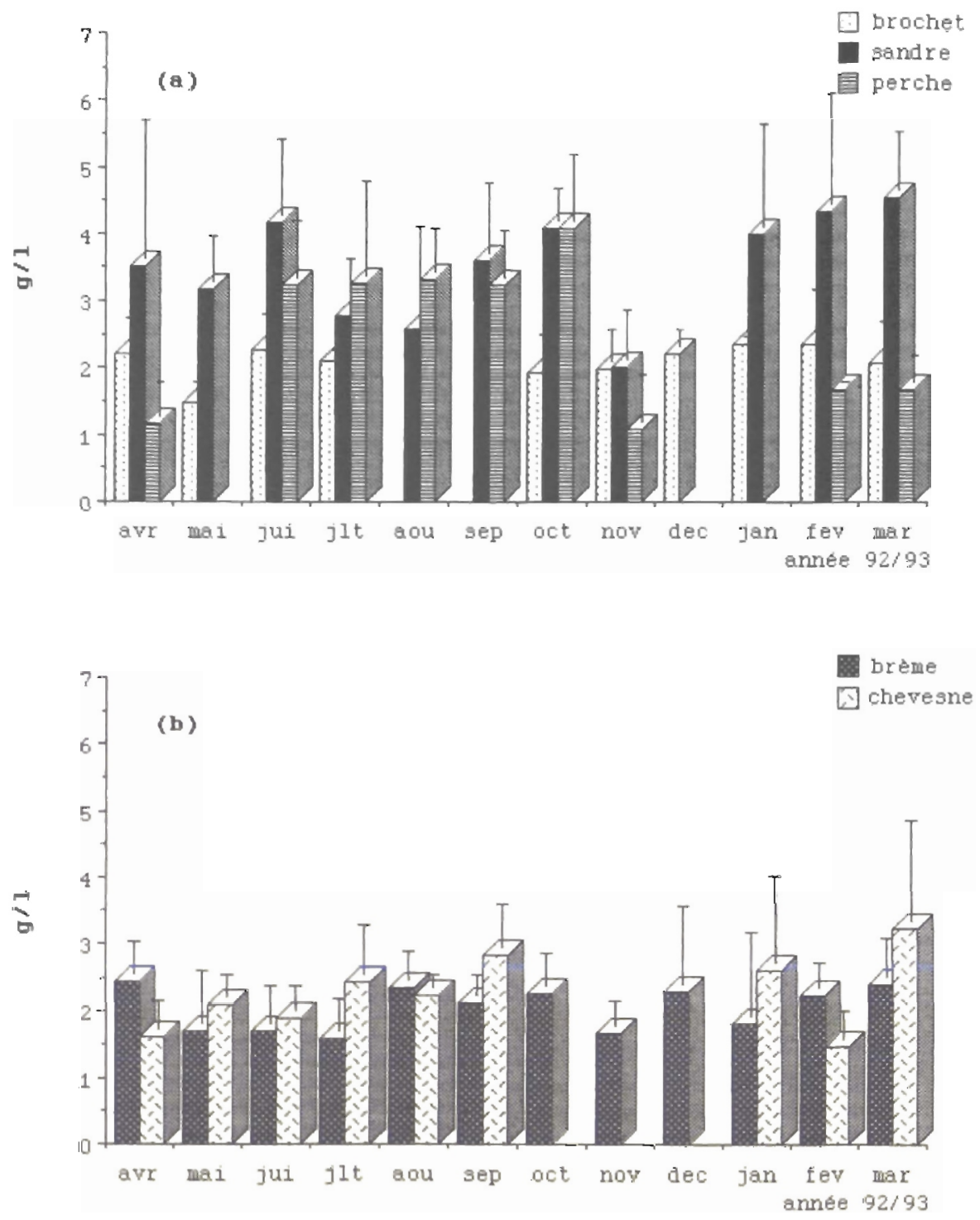

Fig. 11. - Variations monsuelles de la cholestérolémie. Autres détails comme dans Fig. 9. Fig. 11. - Monthly changes in plasma cholesterol levels. Other details as in Fig. 9.

1980; Sandnes et al., 1988) ne peut être confirmée chez les cinq espèces capturées. De plus l'adéquation établie entre le taux de cholestérol plas- matique et le développement des gonades chez des Salmonidés et autres poissons migrateurs (Idler et Tsuyuki, 1958; Robertson et al., 1961; Lewan- 
der et al., 1974; Köck et Bergstrom, 1977; Larsson et Fänge, 1977) n'est pas vérifiée chez ces poissons sédentaires. Des modifications plus ou moins importantes du biotope et de l'état physiologique des animaux (jeûne au cours de la migration reproductrice) doivent certainement contribuer à cette différence entre espèces.

\subsection{Triglycéridémie}

Les recherches, peu nombreuses, sur la triglycéridémie des poissons furent principalement effectuées chez la truite arc-en-ciel, et elles indiquent que, chez cette espèce, les valeurs varient de 1 à $6 \mathrm{~g} / \mathrm{l}$ (Hille, 1982). Ni la méthode de capture utilisée, ni le stress de la manipulation, ni la photopériode ne paraissent influer sur ce paramètre (Bouck et Ball, 1966; Casillas et Smith, 1977; Perrier et al., 1978b, 1979; Hille, 1982; Sandnes et al., 1988). En outre, il n'y aurait que peu de différences interspécifiques (Leamaster et al., 1990).

Nos résultats (fig. 12) témoignent, cependant, de quelques différences entre espèces. D'ailleurs, il existe une certaine similitude entre la variabilité de la cholestérolémie et celle de la triglycéridémie. Ainsi, on observe également une stabilité quasi annuelle des teneurs en triglycérides plasmatiques chez la brème, le brochet et le chevesne (chez ce dernier, les hausses enregistrées en mai et en janvier ne sont pas significatives). Le sandre affiche aussi les taux de triglycérides les plus forts; toutefois, les variations mensuelles sont plus impor- tantes que celles notées pour la cholestérolémie et pourraient être reliées à la quantité de nourriture ingérée (Léger et al., 1979; Frémont et al., 1981; Sandnes et al., 1988; Lemaire et al., 1991). Chez la perche, la triglycéridémie est élevée durant les mois les plus chauds (juin à octobre) ce qui est encore à l'inverse de ce qui a été rapporté pour des Salmonidés en bassins (Shibata et al., 1974; Perrier et al., 1978a). On peut souligner, toutefois, que si, chez les autres espèces, nous n'avons pu déceler un effet de la température sur le taux des triglycérides plasmatiques, le même fait a été signalé chez le carassin (Delahunty et De Vlaming, 1980).

Enfin, une relation entre la triglycéridémie et le cycle de reproduction (Robinson et Mead, 1973; Glueck et al., 1975; De Vlaming, 1983) ne peut être établie chez les cinq espèces capturées.

\subsection{Protéinémie}

De manière générale, le taux des protéines plasmatiques, chez les poissons, est assez stable: la variabilité dans une même population (Hille, 1982) ou entre deux populations d'une même espèce (McCarthy et al., 1973, 1975; Hille, 1982) est faible. Les valeurs mentionnées pour ces animaux sont comprises entre 20 et $60 \mathrm{~g} / \mathrm{l}$ (Field et al., 1943; Bouck et Ball, 1966; Fletcher, 1974; Parent et al., 1976, 1981; Hille, 1982; Sandnes et al., 1988; Leamaster et al., 1990). 

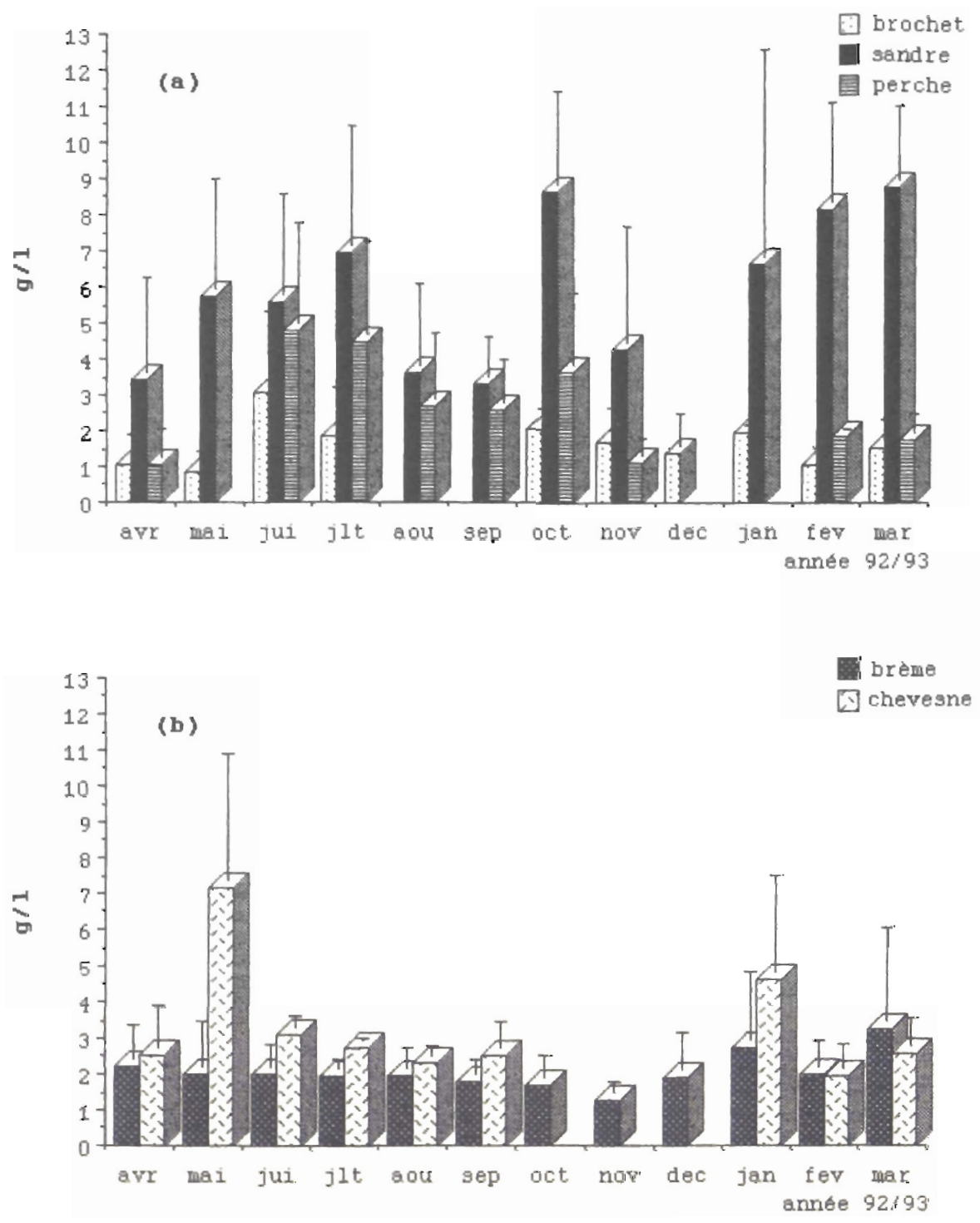

Fig. 12. - Variations mensuelles de la triglycéridémie. Autres détails comme dans Fig. 9. Fig. 12. - Monthly changes in plasma triglyceride levels. Other details as in Fig. 9.

Si les résultats des études de l'effet Bouck et al., 1975; Parent et al., de la température sur la protéinémie 1976; Sauer et Haider, 1977; Hille, des poissons apparaissent contradic- 1982), il ne semble pas qu'il y ait une toires (Sano, 1960; Haider, 1970; influence du stress de la capture ou 
de la manipulation, du taux d'oxygène dissous et de la photopériode sur la teneur en protéines du plasma ( $\mathrm{Ca}$ sillas et Smith, 1978; Perrier et al., 1978b, 1979; Barton et al., 1980; Hille, 1982). Toutefois, une modification quantitative et/ou qualitative de la ration alimentaire, entraînerait des fluctuations de ce composé sanguin (Hille, 1982).

Pour les espèces étudiées, les moyennes annuelles se situent dans les limites des données de la littérature : $28,6 \pm 7,3 \mathrm{~g} / \mathrm{l}$ chez les omnivores et $31,25 \pm 7,6 \mathrm{~g} / \mathrm{l}$ chez les carnivores.

Mais, les variations mensuelles décelées chez le chevesne et les carnassiers sont importantes: le taux des protéines plasmatiques peut passer de 20 à $40 \mathrm{~g} / \mathrm{l}$ ou l'inverse (fig. 13). Ces valeurs de protéinémie correspondent à celles obtenues, en laboratoire, chez des poissons à jeun de $24 \mathrm{~h}$ (environ $20 \mathrm{~g} / 1$ chez la carpe, Creach, 1972) ou nourris (38 +. $3 \mathrm{~g} / \mathrm{l}$ chez la truite, Alexis et al., 1986; 40 $\pm 2 \mathrm{~g} / \mathrm{l}$ chez la brème, Murat et al., 1981), et elles pourraient ainsi être reliées au stade postprandial où se trouvent les animaux au moment de leur capture. De fait, nous avons constaté que, chez les carnassiers et chez le chevesne, des individus d'une même population, capturés au même moment et au même endroit, ne sont jamais dans une même phase digestive; quelle que soit la période étudiée, nous n'avons jamais eu d'animaux ou tous à jeun ou tous bien alimentés. Or, Popova et Sytina (1977) estiment qu'en milieu naturel, les prédateurs (sandre, perche) se nourrissent avant que le repas précédent ne soit entièrement digéré. Mais, d'après nos observations, il semble bien qu'à n'importe quelle époque de l'année, il y ait une période où les carnassiers ainsi que des omnivores comme le chevesne restent un certain temps à jeun puis s'alimentent intensément. On peut donc supposer que le comportement alimentaire de ces animaux soit à l'origine des variations notées. La brème essentiellement planctophage, ayant le tube digestif toujours rempli, a une protéinémie relativement constante au cours de l'année, autour de $30 \mathrm{~g} /$.

\subsection{Insulinémie}

Chez toutes les espèces capturées, les valeurs de l'insulinémie que nous avons obtenues (fig. 14) sont plus faibles que celles rapportées dans la littérature: par exemple, 1 à $4,5 \mathrm{ng} / \mathrm{ml}$ chez la truite arc-en-ciel (Wagner et McKeown, 1982), 4 à $6 \mathrm{ng} / \mathrm{ml}$ chez le saumon (Plisetskaya et al., 1986), jusqu'à 10-12 ng/ml chez le bar (Gutierrez et al., 1987). Cette différence dans les résultats résulte, en grande partie, du système de dosage utilisé. En effet, nous avons évalué le taux d'insuline plasmatique par une technique radioimmunologique établie pour les mammifères, alors que des systèmes homologues sont couramment usités chez les poissons. Mais, l'utilisation de tels systèmes pour une étude réalisée chez plusieurs espèces sauvages de grande taille et donc en nombre limité, est trés difficile voire impossible. Nos données d'analyses 

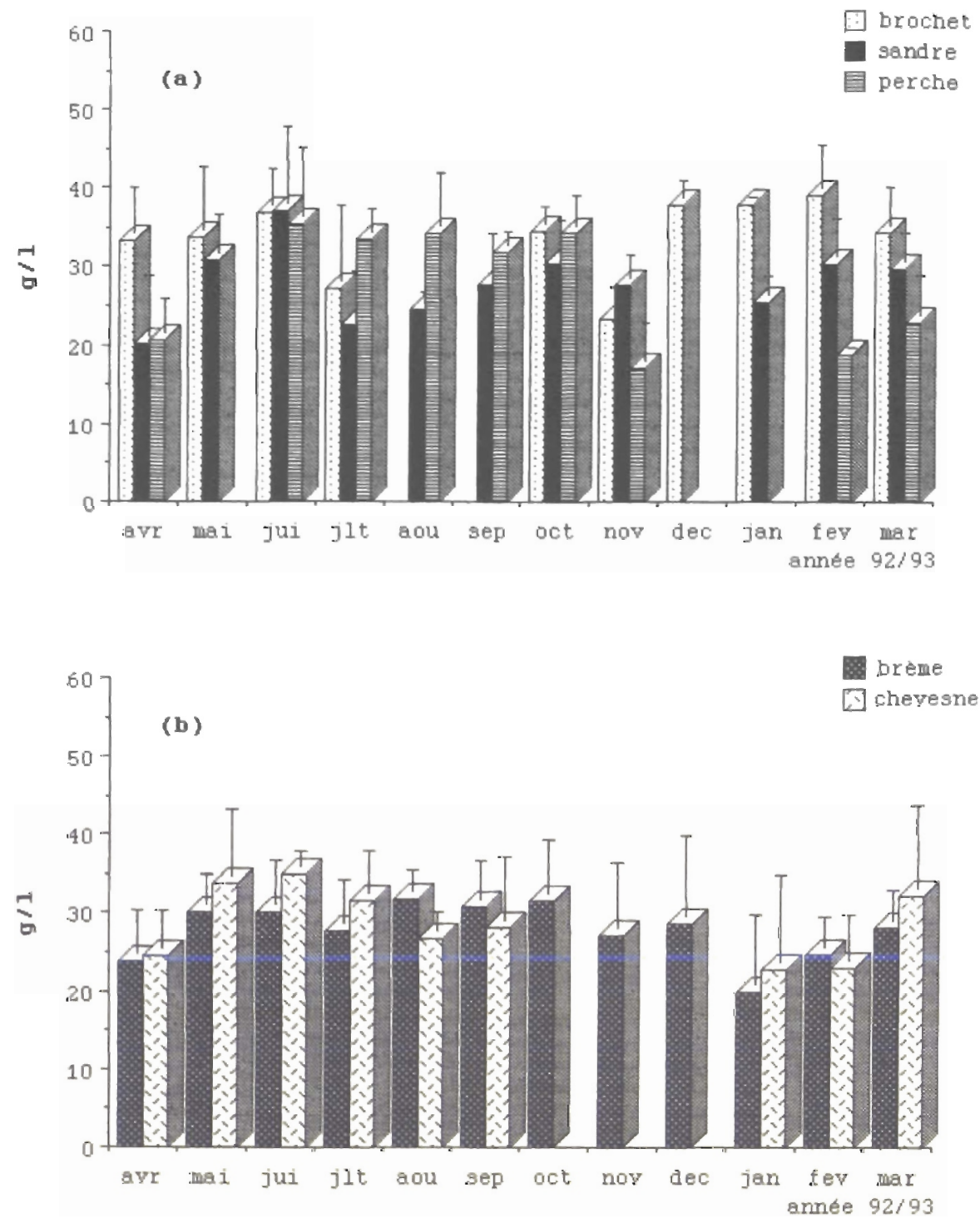

Fig. 13. - Variations mensuelles de la protéinémie. Autres détails comme dans Fig. 9. Fig. 13. - Monthly changes in plasma protein levels. Other details as in Fig. 9.

hétérologues sont donc à considérer plus qualitativement que quantitativement (Sower et al., 1985; Plisetskaya et al., 1986).
Plusieurs auteurs ont montré une relation entre l'insulinémie et le cycle sexuel chez les poissons (Murat et al., 1981; Sower et al., 1985; Tilzey et 

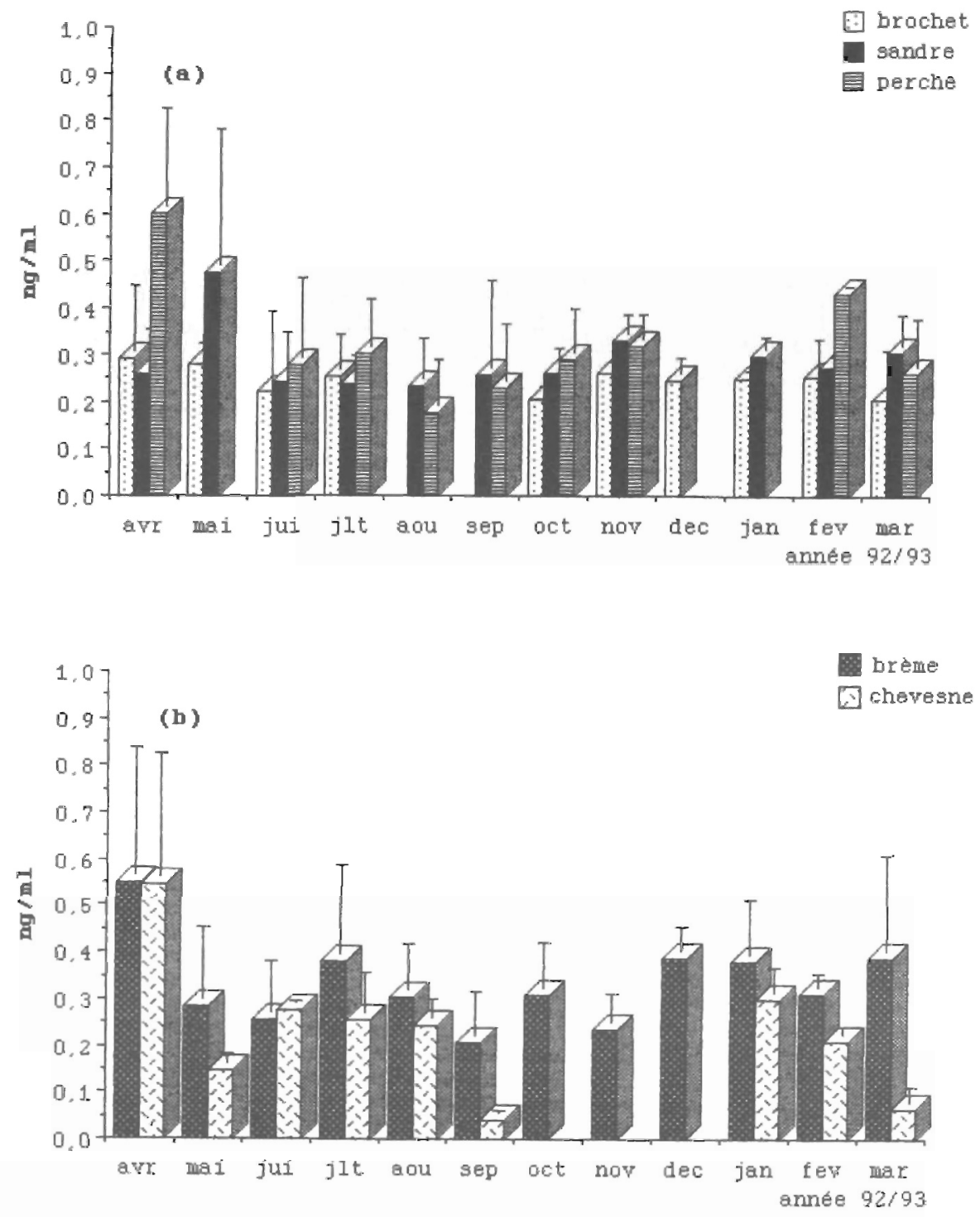

Fig. 14. - Variations mensuelles de l'insulinémie. Autres détails comme dans Fig. 9.

Fig. 14. - Monthly changes in plasma insulin levels. Other details as in Fig. 9.

al., 1985a,b; Gutierrez et al., 1987, à savoir une hausse au moment de 1988; Plisetskaya et al., 1987; Pli- la maturation des gonades puis une setskaya, 1989; Dickhoff et al., 1989), baisse après le frai. Des variations no- 
tables des teneurs en insuline du plasma sont effectivement observées avant la ponte chez les omnivores et au moment du frai chez les Percidés; aucune fluctuation n'est visible chez le brochet qui a frayé en mars 1992 et qui n'a pas encore frayé en 1993.

Cependant, en dehors de la période de reproduction, le taux d'insuline plasmatique apparaît relativement stable chez les carnivores alors que des écarts mensuels importants sont notés chez les omnivores surtout chez le chevesne. Ces différences intra et interspécifiques pourraient être induites par la méthode de capture des animaux (Delahunty et al., 1978; Carrillo et al., 1982; Gutierrez et al., 1984). Si d'aprés Wagner et McKeown (1982) ou Gapp (1987), les catécholamines libérées à la suite d'un stress inhibent la sécrétion de l'insuline, selon Tilzey et al. (1985a,b), leur action sur la sécrétion hormonale serait double: en fonction des taux circulants, il y aurait inhibition ou stimulation, ce qui pourrait expliquer, chez les espèces étudiées, non seulement les divergences observées dans l'évolution de l'insulinémie mais aussi, pour une part, les faibles valeurs obtenues.

\section{BIBLIOGRAPHIE}

Alexis M., Thedchari V. \& Papaparaskeva-Papoutsoglou E., 1986. Effect of diet composition and protein levels on growth, body composition, haematological characteristics and cost of pro- duction of rainbow trout. Aquaculture, 58 : 75-85.

Allen J.R.M. \& Wootton R.J., 1982. EHect of food on the growth of carcass, liver and ovary in the female (Gasterosteus aculeatus L.). J. Fish. Biol., 21 : 537547.

Arias-Gonzalez E. \& Richeux C., 1990. Etude préliminaire du régime alimentaire du gardon (Rutilus rutilus L.) et de la perche (Perca fluviatilis L.) de la retenue de Pareloup (Aveyron): rythme de prise alimentaire en milieu naturel. D.E.A., UPS Toulouse: $64 \mathrm{pp}$.

Barnhart R.A., 1969. Effects of certain variables on hematological characteristics of rainbow trout. Trans. Am. Fish. Soc., 98 : 411-418.

Barton B., Peter R. \& Paulencu C., 1980. Plasma cortisol levels of fingerling rainbow trout (Salmo gairdnerl) at rest, and subjected to handling confinement, transport and stocking. Can. J. Fish. Aquat. Sci., 37 : 805-811.

Bau F., Parent J.P. \& Vellas F., 1994. Evolution saisonnière de paramètres sanguins chez divers Téléostéens capturés dans une retenue. Ichtyophysiologica Acta, 17 : 63-89.

Baucheff-Nielsen P., 1988. Contribution à l'écologie du zooplancton du lac de Pareloup. Thèse $3^{e}$ cycle, U.P.S. Toulouse: $104 \mathrm{pp}$.

Black D. \& Love R.M., 1986. The sequential mobilisation and restoration of energy reserves in tissues of Atlantic cod during starvation and refeeding. $J$. Comp. Physiol., 156B : 469-479.

Boivin T.G. \& Power G., 1990. Winter condition and proximate composition of anadromous Arctic charr (Salvelinus alpinus) in eastern Ungava bay, Quebec. Can. J. Zool., 68: 2284-2289.

Bouche G., Vellas F. \& Serfaty A., 1973. Influence du jeûne total prolongé suivi d'une période de "réalimentation " sur les acides nucléiques et les protéines du muscle blanc de la carpe commune 
(Cyprinus carpio L.). C. r. Séanc. Soc. Biol., 167(1) : 148.

Bouck G.R. \& Ball R.C., 1966. Influence of capture methods on blood characteristics and mortality in the rainbow trout (Salmo gairdneri). Trans. Am. Fish. Soc., 95 : 170-176.

Bouck G.R., Schneider P.W., Jacobson J. \& Ball R.C., 1975. Characterization and subcellular localization of leucine aminonaphthylamidase (LAN) in rainbow trout (Salmo gairdneri). J. Fish. Res. Board Can., 32 : 1289-1295.

Brett J.R., Shelbourn J.E. \& Shoop C.T., 1969. Growth rate and body composition of fingerling sockeye salmon (Oncorhynchus nerka) in relation to temperature and ration size. J. Fish. Res. Board. Can., 26 : 2363-2394.

Bulow F.J. \& Coburn C.B., 1976. Liver body weight ratios as indicators of seasonal growth variations in two Lepomis macrochirus (Centrarchidae) populations. ASB (Assoc. Sowtheast. Biol.) Bull., 23 : 47.

Bulow F.J., Coburn C.B. \& Cobb J.R., 1978. Comparisons of two bluegill populations by means of the RNA-DNA ratio and liver somatic index. Trans. Am. Fish. Soc., 107 : 799-803.

Caminade V., 1986. Recherches sur l'état nutritionnel de deux espèces de poissons de la retenue de Pareloup (Aveyron) : le gardon (Rutilus rutilus L.) et la perche (Perca fluviatilis L.). Thèse $3^{\ominus}$ cycle, INP.ENSA Toulouse: $79 \mathrm{pp}$.

Carrillo M., Zanuy S. \& Herrera E., 1982. Growth and diurnal variations in metabolic parameters in the starved bass, Dicentrarchus labrax, after experimental feeding. Comp. Biochem. Physiol, 72A : 11-16.

Casillas E. \& Smith L.S., 1977. Effect of stress on blood coagulation and haematology in rainbow trout (Salmo gairdnerl). J. Fish Biol., 10 : 481-491.

Caulton M.S. \& Bursell E., 1977. The relationship between changes in condition and body composition in young
Tilapia rendalli Boulanger. J. Fish Biol., 11: 143-150.

Chappaz R., Brun G. \& Olivari G., 1989. Contribution à l'étude du régime alimentaire, de la croissance et de la fécondité de la perche (Perca fluviatilis L.) dans un lac oligotrophe de région tempérée. Revue des sciences de l'eau, 2 : 95-107.

Cowey C.B. \& Tacon A.G.J., 1983. Fish nutrition - relevance to invertebrates. In: "Proceedings, Second International Conference on Aquaculture Nutrition": Biochemical and Physiological Approaches to Shellfish Nutrition". Louisiana State University, Division of Continuing Education, Baton Rouge, LA. G.D. Pruder, C.J. Langdon and D.E. Conklin ed. : 13-30.

Craig J.F., 1977. The body composition of adult perch, Perca fluviatilis in Windermere, with reference to seasonal changes and reproduction. J. Anim. Ecol., 46 : 617-632.

Craig J.F., 1985. Aging in fish. Can. J. Zool., $63: 1-8$.

Craig J.F., Smiley K. \& Babaluk J.A., 1989. Changes in the body composition with age of goldeye (Hiodon alosoides). Can. J. Fish. Aquat. Sci, 46 : 853-858.

Creach Y., 1972. Le jeûne expérimental chez la carpe: métabolisme azoté et équilibre hydrominéral. Thèse d'état, UPS Toulouse: $223 \mathrm{pp}$.

Crupkin M., Montecchia C.L. \& Trucco R.E., 1988. Seasonal variations in gonadosomatic index, liver-somatic index and myosin/actin ratio in actomyosin of mature hake (Merluccius hubbsi). Comp. Biochem. Physiol, 89A(1) : 7 10.

Dauba F., 1983. Etude hydrobiologique du lac de Pareloup. C.r. ENSAT/EDF REAM: $64 \mathrm{pp}$.

Dawson A.S. \& Grimm A.S., 1980. Quantitative seasonal changes in the protein, lipid and energy content of the carcass, ovaries and liver of adult fe- 
male plaice, Pleuronectes platessa $\mathrm{L}$. J. Fish Biol., 16 : 493-504.

Delahunty G., Olcese J., Prack M., Vodicnik M.J., Schreck C.B. \& De Vlaming V.L., 1978. Diurnal variations in the physiology of the goldfish, Carassius auratus L. J. Interdiscipl. Cycle Res., $9: 73-88$.

Delahunty G. \& De Vlaming V.L., 1980. Photoperiod-temperature interactions on liver and plasma metabolites in the goldfish, Carassius auratus. Comp. Biochem. Physiol., 66A : 507-512.

De Silva S.S., Gunasekera R.M. \& Shim K.F., 1991. Interactions of varying dietary protein and lipid levels in young red tilapia: evidence of protein sparing. Aquaculture, $95: 305-318$.

De Vlaming V.L., 1983. Oocyte development patterns and hormonal involvements among teleosts. In: "Control Processes in Fish Physiology". J.C. Rankin, T.J. Pitcher and R.T. Duggan ed., New-York: 176-199.

Dickhoff W.W., Yan L., Plisetskaya E.M., Sullivan C.V., Swanson P., Hara A. \& Bernard M.G., 1989. Relationship between metabolic and reproductive hormones in salmonid fishes. Fish Physiol. Biochem., 7 : 147-155.

Dobson S.H. \& Holmes R.M., 1984. Compensatory growth in the rainbow trout, (Salmo gairdneri Richardson). J. Fish Biol., 25 : 649-656.

Dos Santos J., Burkow I.C. \& Jobling M., 1993. Patterns of growth and lipid deposition in cod (Gadus morhua L.) fed natural prey and fish-based feeds. Aquaculture, 110 : 173-189.

E.I.F.A.C., 1975. Symposium on the methodology for the survey, monitoring and appraisal of fishery resources in lakes and large rivers. Panel reviews and relevant papers. E.I.F.A.C. Tech. Pap., 23 (I et II) : $746 \mathrm{pp}$.

Eliassen J.E. \& Vahl O., 1982. Seasonal variations in biochemical composition and energy content of liver, gonad and muscle of mature and immature cod,
Gadus morhua (L.) from Balsfjorden, Northern Norway. J. Fish. Biol, 20 : 707-716.

Elliott J.M., 1976. Body composition of brown trout (Salmo trutta L.) in relation to temperature and ration size. $J$. Anim. Ecol., 45 : 273-289.

Ferroni J.M., Bau F., Parent J.P. \& Vellas F., 1992. Variations de la composition du soma chez la perche (Perca fluviatilis) capturée, à différentes saisons, dans la retenue de Pareloup (Aveyron). Ichtyophysiologica Acta, 15 : 6978.

Field J.B., Elvehjem C.A. \& Juday C., 1943. A study of the blood constituents of carp and trout. J. Biol. Chem., 148 : 261-269.

Fletcher G.L., 1975. The effects of capture, "stress" and storage of whole blood on the red blood cells, plasma proteins, glucose and electrolytes of the winter flounder (Pseudopleuronectes americanus). Can. J. Zool., 53 : 197-206.

Frémont L. \& Léger L., 1981. Le transport des lipides plasmatiques. In: "Nutrition des Poissons", Actes du Colloque C.N.E.R.N.A. (mai 1979). CNRS ed., Paris: 263-282.

Frémont L., Léger C., Boudon M. \& Gozzelino M.T., 1981. Fatty acid composition of lipids in the trout. -II. Fractionation and analysis of plasma lipoproteins. Comp. Biochem. Physiol., 69B : 107-113.

Francisco P. \& Rey J., 1994. Etude du peuplement zooplanctonique de la retenue de Pareloup (Aveyron, France). Hydroécol. Appl., 6(1/2): 175-196.

Gapp D.A., 1987. Endocrine and related factors in the control of metabolism in nonmammalian vertebrates. In: "Fundamentals of comparative vertebrate endocrinology", I. Chester-Jones, P.M. Ingleton and J.G. Phillips ed., Plenum press, New York/London : 511-660.

Gatlin D.M., 1987. Whole-body amino acid composition and comparative aspects 
of amino acid nutrition of the goldfish, golden shiner and fathead minnow. Aquaculture, $60: 223-229$.

Gerking S.D., 1955. Influence of rate of feeding on body composition and protein metabolism of bluegill sunfish. Physiol. Zoöl., 28(4) : 267-282.

Gheracopol O., 1972. Dinamica aminoacizilor din musculatura crapului de cultura. Bul. Cercetari Pisc., 31 : 55-78.

Gillet C., 1989. Le déroulement de la fraie des principaux poissons lacustres. Hydroécol. Appl., 1/2 : 117-143.

Glueck C.J., Fallat R.W. \& Scheel D., 1975. Effects of estrogenic compounds on triglyceride kinetics. Metabolism, 24 : 537-545.

Goldspink C.R., 1979. The population density, growth rate and production of roach Rutilus rutilus (L.) in Tjeukemeer, The Netherlands. J. Fish. Biol., 15 : 473-498.

Gutierrez J., Carrillo M., Zanuy S. \& Planas J., 1984. Daily rhythms of insulin and glucose levels in the plasma of sea bass Dicentrarchus labrax after experimental feeding. Gen. Comp. Endocrinol., 55 : 393-397.

Gutierrez J., Fernandez J., Carrillo M., Zanuy S. \& Planas J., 1987. Annual cycle of plasma insulin and glucose of sea bass, Dicentrarchus labrax L. Fish Physiol. Biochem., 4(3) : 137-141.

Gutierrez J., Fernandez J. \& Planas J., 1988. Seasonal variations of insulin and some metabolites in dogfish plasma, Scyliorhinus canicula L. Gen. Comp. Endocrinol., $70: 1-8$.

Haider G., 1970. Hämatologische Beobachtungen an Regenbogenforellen (Salmo gairdneri Rich.). -II. Der Blutzuckerspiegel. Z. Fischerei, 18 : 209-216.

Heidinger R.C. \& Crawford S.D., 1977. Effect of temperature and feeding rate on the liver-somatic index of the largemouth bass (Micropterus salmoides). J. Fish. Res. Board Can., 34 : 633-638.
Hemre G.I., Lambertsen G. \& Lie O., 1991. The effect of dietary carbohydrate on the stress response in cod (Gadus morhua). Aquaculture, 95: 319-328.

Hille S., 1982. A literature review of the blood chemistry of rainbow trout, Salmo gairdneri Rich. J. Fish Biol., 20 : 535-569.

Hilton J.W., 1982. The effect of pre-fasting diet and water temperature on liver glycogen and liver weight in rainbow trout (Salmo gairdneri Richardson), during fasting. J. Fish Biol., 20 : 69-78.

Hokanson K.E.F., 1977. Temperature requirements of some percids and adaptations to the seasonal temperature cycle. J. Fish. Res. Board Can., 34 : 1524-1550.

Huisman E.A., Klein Breteler J.G.P., Visman M.M. \& Kanis E., 1979. Retention of energy, protein, fat and ash in growing carp (Cyprinus carpio) under different feeding and temperature regimes. In: "Finfish Nutrition and Fishfeed technology". J.E. Halver and K. Tiews ed., 1 : 175-188.

Hung S.S.O., Conte F.S. \& Hallen E.F., 1993. Effects of feeding rates on growth, body composition and nutrient metabolism in striped bass (Morone saxatilis) fingerlings. Aquaculture, 112 : 349-361.

Idler D.R. \& Tsuyuki H., 1958. Biochemical studies on sockeye salmon during spawning migration. -I. Physical measurements, plasma cholesterol and electrolyte levels. Can. J. Biochem. Physiol., 36 : 783-791.

Ince B.W. \& Thorpe A., 1975. Hormonal and metabolite effects on plasma free fatty acids in the Northern pike, Esox lucius L. Gen. Comp. Endocrinol., 27 : 144-152.

Jobling M., Jorgensen E.H. \& Siikavuopio S.I., 1993. The influence of previous feeding regime on the compensatory growth response of maturing and im. 
mature Arctic charr (Salvelinus alpinus). J. Fish Biol., 43 : 409-419.

Jrad A., 1989. Phytoplancton et production primaire dans le lac de Pareloup (Aveyron). Thèse 3ème cycle, U.P.S. Toulouse: $159 \mathrm{pp}$.

Jürss K., 1979. Effects of temperature, salinity, and feeding on aminotransferase activity in the liver and white muscle of rainbow trout (Salmo gairdneri Richardson). Comp. Biochem. Physiol., 64B : 213-218.

Karas P., 1990. Seasonal changes in growth and standard metabolic rate of juvenile perch, Perca fluviatilis L. J. Fish Biol., 37 : 913-920.

Kaushik S.J. \& Luquet P., 1979. Influence of dietary amino acid patterns on the free amino acid contents of blood and muscle of rainbow trout (Salmo gairdneri R.). Comp. Biochem. Physiol., 64B : 175-180.

Knapp E. \& Weiser W., 1980. Looking for "Metabolic thermometers" in poikilothermic animals. Naturwissenschafter, 67: 313-314.

Knapp E. \& Weiser W., 1981. Effects of temperature and food on the free amino acids in tissues of Roach (Rutilus rutilus L.) and Rudd (Scardinius erythrophthalmus L.). Comp. Biochem. Physiol., 68A : 187-198.

Köck H.J. \& Bergstrom E., 1977. Plasma cholesterol in the precocious males of Salmo salar. In: "Protides of the Biological Fluids", Proc $25^{\text {th }}$ Colloquium Brugge. H. Peeters ed., Pergamon Press, Oxford: 483-486.

Lane H.C., 1979. Progressive changes in haematology and tissue water of sexually mature trout, Salmo gairdneri Richardson during the autumn and winter. J. Fish Biol., 15 : 425-436.

Larsson A. \& Fänge R., 1977. Cholesterol and free fatty acids (FFA) in the blood of marine fish. Comp. Biochem. Physiol., 57B : 191-196.

Leamaster B.R., Brock J.A., Fujioka R.S. \& Nakamura R.M., 1990. Hematologic and blood chemistry values for Sarotherodon melanotheron and a red hybrid tilapia in freshwater and seawater. Comp. Biochem. Physiol, 97A(4): 525-529.

Le Cren E.D., 1951. The length-weight relationship and seasonal cycle in gonad weight and condition in the perch (Perca fluviatilis). J. Anim. Ecol., 20 : 201 219.

Léger C., Frémont L., Bergot P. \& Flanzy J., 1979. Quelques recherches sur la digestion, l'absorption, le transport et le stockage des lipides chez le poisson. Interêt d'une biochimie comparée des lipides. Méd. Nutr., 15(1) : 61-71.

Leibson L.G. \& Plisetskaya E.M., 1968. Effect of insulin on blood sugar level and glycogen content in organs of some cyclostomes and fish. Gen. Comp. Endocrinol., 11 : 381-392.

Lemaire P., Drai P., Mathieu A., Lemaire S., Carriere S., Giudicelli J. \& Lafaurie M., 1991. Changes with different diets in plasma enzymes (GOT, GPT, LDH, ALP) and plasma lipids (cholesterol, triglycerides) of sea bass (Dicentrarchus labrax). Aquaculture, 93 : 63-75.

Lewander K., Dave G., Johansson-Sjobeck M.L., Larsson A. \& Lidman U., 1974. Metabolic and hematological studies on the yellow and silver phases of the European eel, Anguilla anguilla L. -I. Carbohydrate, lipid, protein and inorganic ion metabolism. Comp. Biochem. Physiol., 47B : 571581.

Lind E.A., 1974. Seasonal variation in weight and activity of the freshwater fishes Perca fluviatilis and Esox lucius. Nordic Council Artct. Med. Rep., 10 : 65-66.

Love R.M., 1970. "The chemical biology of fishes", 1. Academic Press, London/New-York : 547 pp.

Love R.M., 1980. "The chemical biology of fishes", 2. Academic Press, London/New-York : 943 pp. 
McCarthy D.H., Stevenson J.P. \& Roberts M.S., 1973. Some blood parameters of the rainbow trout (Salmo gairdneri Richardson). I. The Kamloops variety. J. Fish Biol., 5 : 1-8.

McCarthy D.H., Stevenson J.P. \& Roberts M.S., 1975. Some blood parameters of the rainbow trout (Salmo gaidneri Richardson). II. The Shasta variety. J. Fish Biol., 7 : 215-219.

Medford B.A. \& Mackay W.C., 1978. Protein and lipid content of gonads, liver and muscle of northern pike (Esox lucius) in relation to gonad growth. $J$. Fish. Res. Board Can., 35 : 213-219.

Méndez G. \& Wieser W., 1993. Metabolic responses to food deprivation and refeeding in juveniles of Rutilus rutilus (Teleostei: Cyprinidae). Env. Biol. Fish., 36 : 73-81.

Miglavs I. \& Jobling M., 1989. The effects of feeding regime on proximate body composition and patterns of energy deposition in juvenile arctic charr (Salvelinus alpinus). J. Fish Biol., 35 : 111.

Miguel J.L., Agapito M.T. \& Recio J.M., 1988. Sex differences of hematological and biochemical parameters in healthy rainbow trout (Salmo gairdneri, R.). Rev. esp. Fisiol., 44(2) : 215-220.

Muje P., Agren J.J., Lindqvist O.V. \& Hänninen O., 1989. Fatty acid composition of vendace (Coregonus albula L.) muscle and its plankton feed. Comp. Biochem. Physiol., 92B(1) : 75-79.

Murat J.C., Plisetskaya E.M. \& Woo N.Y.S., 1981. Endocrine control of nutrition in cyclostomes and fish. Comp. Biochem. Physiol., 68A : 149-158.

Newsome G.E. \& Leduc G., 1975. Seasonal changes of fat content in the yellow perch (Perca flavescens) of two Laurentian lakes. J. Fish. Res. Board Can., 32(11) : 2214-2221.

Nikolsky G.V., 1963. "The ecology of fishes". Academic Press, London/NewYork : $352 \mathrm{pp}$.
Overstreet R.M., 1983. Aspects of the biology of the spotted seatrout (Cynoscion nebulosus), in Mississippi. Gulf Research Reports, Suppl' 1: 1-43.

Papageorgiou N.K., 1979. The lenghtweight relationship, age, growth and reproduction of the roach (Rutilus rutilus) in lake Volvi. J. Fish Biol., 14 : 529-538.

Parent J.P., Bouche G. \& Vellas F., 1976. Effet du réchauffement artificiel des eaux sur quelques paramètres physiologiques de deux Téléostéens d'eau douce: le gardon et la perche. Cah. Lab. Hydrobiol. Montereau, 3 : 5-14.

Parent J.P. \& Vellas F., 1981. Effets de variations thermiques chez la truite arc-en-ciel (Salmo gairdneri, Rich.). Cah. Lab. Hydrobiol. Montereau, 11: 29-40.

Parent J.P., Creach Y. \& Vellas F., 1981. Effets de brusques variations thermiques chez la carpe (Cyprinus carpio L). Cah. Lab. Hydrobiol. Montereau, 11 : 19-28.

Parent J.P., Caminade V. \& Vellas F., 1985. Evaluation de l'état nutritionnel du gardon (Rutilus rutilus) et de la perche (Perca fluviatilis) capturés dans la retenue de Pareloup. Elude préliminaire. Ichtyophysiologica Acta, 9 : 202221.

Parent J.P., Ferroni J.M., Bau F. \& Vellas F., 1993. Variations quantitatives des protéines, lipides et cendres somatiques chez le gardon capturé, à différentes saisons, dans une retenue mésotrophe. In: "Fish Nutrition in Practice", S.J. Kaushik and P. Luquet ed., INRA, Paris: $307-312$.

Parent J.P., Ferroni J.M., Escorihuela D. \& Vellas F., 1993. Teneurs en acides aminés du soma, à différentes saisons, chez deux espèces sauvages: la perche (Perca fluviatilis) et le gardon (Rutilus rutilus). In: "Fish Nutrition in Practice", S.J. Kaushik and P. Luquet ed., INRA, Paris: 313-318. 
Patent G.J., 1970. Comparison of some hormonal effects on carbohydrate metabolism in an elasmobranch (Squalus acanthias) and a holocephalan (Hydrolagus colliel). Gen. Comp. Endocrinol., $14: 215-242$.

Pearson M.P. \& Stevens E.D., 1991. Size and hematological impact of the splenic erythrocyte reservoir in rainbow trout, Oncorhynchus mykiss. Fish Physiol. Biochem., 9(1) : 39-50.

Penczak T., Molinski M., Kusto E., Ichniowska B. \& Zalewski M., 1977. The ecology of roach, Rutilus rutilus (L.), in the barbel region of the polluted Pilica river. -III. Lipids, protein, total nitrogen and caloricity. Ekol. pol., 25(1) : 75-88.

Penczak T., Molinski M. \& Oska M., 1978. Materials for the ecology of the dace (Leuciscus leuciscus L.) from a polluted river in the region of barbel (the river Pilica). -III. Lipids, proteins, total nitrogen and caloric value. Acta Hydrobiol., 20 : 97-108.

Perez J., Zanuy S. \& Carrillo M., 1988. Effects of diet and feeding time on daily variations in plasma insulin, hepatic c-AMP and other metabolites in a teleost fish, Dicentrarchus labrax, L. Fish Physiol. Biochem., 5(4) : 191-197.

Perez J., Gutierrez J., Carrillo M., Zanuy S. \& Fernandez J., 1989. Effect of bonito insulin injection on plasma immunoreactive glucagon levels and carbohydrate and lipid metabolism of sea bass (Dicentrarchus labrax). Comp. Biochem. Physiol., 94A(1) : 3336.

Perrier H., Perrier C. \& Gras J., 1971. Etude de l'hyperglycémie adrénalique chez la truite arc-en-ciel d'élevage (Salmo gairdneri Richardson). Action des substances adrénolytiques. C.r. Séanc. Soc. Biol., 165 : 2141-2144.

Perrier H., Perrier G., Gras J. \& Peres G., 1978a. Etude quantitative de la composition du plasma, en particulier des fractions protéiques, chez la truite arc-en-ciel d'élevage acclimatée à $9^{\circ} \mathrm{C}$ et à $21^{\circ} \mathrm{C}$ au cours de l'hiver et du printemps. Cah. Lab. Hydrobiol. Monterau, $7:$ 27-32.

Perrier C., Terrier M. \& Perrier H., 1978b. A time-course study of the effects of angling stress on cyclic AMP, lactate and glucose plasma levels in the rainbow trout (Salmo gairdneri Richardson) during a 64 hour recovery period. Comp. Biochem. Physiol., 60A : 217219.

Perrier C., Perrier H. \& Terrier M., 1979. Les taux plasmatiques d'AMP cyclique et de glucose chez la truite (Salmo gairdneri Richardson) soumise à diverses formes d'agression. Ichtyophysiologica Acta, 3 : 97-103.

Persson L., 1987. Effects of habitat and season on competitive interactions between roach (Rutilus rutilus) and perch (Perca fluviatilis). Oecologia (Berlin), 73 : 170-177.

Plisetskaya E.M., Dickhoff W.W., Paquette T.L. \& Gorbman A., 1986. The assay of salmon insulin by homologous radioimmunoassay. Fish Physiol. Biochem., 1(1) : 37-43.

Plisetskaya E.M., Donaldson E.M. \& Dye H.M., 1987. Plasma insulin levels during the spawning migration of the pink salmon, Oncorhynchus gorbuscha. J. Fish Biol., 31 : 21-26.

Plisetskaya E.M., 1989. Physiology of fish endocrine pancreas. Fish Physiol. Biochem., 7 : 39-48.

Plisetskaya E.M., Buchelli-Narvaez L.I., Hardy R.W. \& Dickhoff W.W., 1991. Effects of injected and dietary arginine on plasma insulin levels and growth of Pacific salmon and rainbow trout. Comp. Biochem. Physiol., 98A(1): 165-170.

Popova O.A. \& Sytina L.A., 1977. Food and feeding relations of Eurasian perch (Perca fluviatilis) and pikeperch (Stizostedion lucioperca) in various waters of the USSR. J. Fish. Res. Board Can., 34 : 1559-1570. 
Randall D.J., 1982. The control of respiration and circulation in fish during exercice and hypoxia. J. Exp. Biol., 100 : 275-288.

Richeux C., Arias-Gonzalez J.E. \& Tourenq J.N., 1992. Etude du régime alimentaire des gardons (Rutilus rutilus) du lac de Pareloup (Massif Central, France). Annls. Limnol., 28(3) : 245 252.

Robertson O.H., Krupp M.A., Favour C.B., Hane S. \& Thomas S.F., 1961. Physiological changes occurring in the blood of the Pacific salmon (Oncorhynchus tshawytscha) accompanying sexual maturation and spawning. Endocrinology, 68 : 733-746.

Robinson J.S. \& Mead J.F., 1973. Lipid absorption and deposition in rainbow trout (Salmo gairdnerı). Can. J. Biochem., 51 : 1050-1058.

Salençon M.J., Thébault J.M. \& Capblancq J., 1987-1990. Etude de la retenue de Pareloup: synthèse des travaux réalisés dans le cadre de la convention E.D.F./Ministère de l'Environnement. Rapport E.D.F., HE/3190/23, 40 pp.

Sandnes K., Lie O. \& Waagbo R., 1988. Normal ranges of some blood chemistry parameters in adult farmed Atlantic salmon, Salmo salar. J. Fish Biol., 32 : 129-136.

Sano T., 1960. Haematological studies of culture fishes in Japan. -II. Seasonal variations of the blood constituents of rainbow trout. J. Tokyo Univ. Fish., 46 : 67-75.

Sauer D.M. \& Haider G., 1977. Enzyme activities in the serum of rainbow trout, Salmo gairdneri Richardson; the effects of water temperature. J. Fish Biol., 11 : 605-612.

Schwalme K. \& Mackay W.C., 1985. The influence of angling-induced exercise on the carbohydrate metabolism of northern pike (Esox lucius L.). J. Comp. Physiol., 156B : 67-75.
Schwalme K. \& Mackay W.C., 1990. Mechanisms that elevate the glucose concentration of muscle and liver in yellow perch (Perca flavescens Mitchill) after exercise-handling stress. Can. J. Zool., 69 : 456-461.

Schwartz F.J. \& Kirchgessner M., 1988. Amino acid composition of Carp (Cyprinus carpio L.) with varying protein and energy supplies. Aquaculture, 72 : 307-317.

Shibata N., Kinumaki T. \& Ichimura H., 1974. Triglyceride, cholesterol, free fatty acid, glucose and protein contents in plasma of cultured rainbow trout. Bull. Tokai reg. Fish. Res. Lab., $77: 77-87$.

Shimma Y., Shimma H. \& Ikeda K., 1982. Plasma constituents of 1-year-old rainbow trout raised with fish meal and SCP combined feeds. Bull. Japan. Soc. Sci. Fish., 48(6) : 805-810.

Smit G.L., Hattingh J. \& Ferreira J.T., 1981. The physiological responses of blood during thermal adaptation in three freshwater fish species. J. Fish Biol., 19 : 147-160.

Sower S.A., Plisetskaya E.M. \& Gorbman A., 1985. Changes in plasma steroid and thyroid hormones and insulin during final maturation and spawning of the sea lamprey, Petromyzon marinus. Gen. Comp. Endocrinol., 58 : 259-269.

Storebakken T., Hung S.S.O., Calvert C.C. \& Plisetskaya E.M., 1991. Nutrient partitioning in rainbow trout at different feeding rates. Aquaculture, 96 : 191203.

Sweeting R.M., Wagner G.F. \& Mckeown B.A., 1985. Changes in plasma glucose, amino acid nitrogen and growth hormone during smoltification and seawater adaptation in coho Salmon, Oncorhynchus kisutch. Aquaculture, 45 : 185-197.

Tanasichuk R.W. \& Mackay W.C., 1989. Quantitative and qualitative characteristics of somatic and gonadal growth of yellow perch, Perca flavescens, 
from lac Ste Anne, Alberta. Can. J. Fish. Aquat. Sci., 46 : 989-994.

Thorpe J.E., 1977. Morphology, physiology, behavior, and ecology of Perca fluviatilis $L$. and $P$. flavescens Mitchill. J. Fish. Res. Board Can., 34 : 15041514.

Tilzey J.F., Waights V. \& Holmes R., 1985a. The development of a homologous teleost insulin radioimmunoassay and its use in the study of adrenaline on insulin secretion from isolated pancreatic islet tissue of the rainbow trout, Salmo gairdneri (R.). Comp. Biochem. Physiol., 81A(4) : 821-825.

Tilzey J.F., Waights V. \& Holmes R., 1985b. Adrenergic control of insulin release from isolated islet tissue in the rainbow trout, Salmo gairdneri (R.). Gen. Comp. Endocrinol., 59 : 460-467.

Townsend C.R. \& Perrow M.R., 1989. Eutrophication may produce population cycles in roach, Rutilus rutilus (L.), by two contrasting mechanisms. J. Fish Biol., 34: 161-164.

Tveranger B., 1985. Variation in growth rate, liver weight and body composition at first sexual maturity in rainbow trout. Aquaculture, 49 : 89-99.

Van Vuren J.H.J. \& Hattingh J., 1978. A seasonal study of the haematology of wild freshwater fish. J. Fish Biol., 13 : 305-313.

Wagner G.F. \& Mckeown B.A., 1982. Changes in plasma insulin and carbohydrate metabolism of zinc-stressed rainbow trout, Salmo gairdneri. Can. J. Zool., 60 : 2079-2084.

Weatherley A.H. \& Gill H.S., 1983. Protein, lipid, water and caloric contents of immature rainbow trout, Salmo gairdneri Richardson, growing at different rates. J. Fish Biol., 23 : 653-673.
Weatherley N.S., 1987. The diet and growth of O-group dace, Leuciscus leuciscus (L.), and roach, Rutilus rutilus (L.), in a lowland river. J. Fish Biol., $30: 237-247$.

Weatherley N.S. \& Gill H.S., 1987. "The Biology of Fish Growth". Academic Press, London : $443 \mathrm{pp}$.

Wedemeyer G. \& Chatterton K., 1970. Some blood chemistry values for the rainbow trout (Salmo gairdneri). J. Fish. Res. Board Can., 27(6) : 11621164.

Weiser W., Krumschnabel G., Ojwang-Okwor J.P., 1992. The energetics of starvation and growth after refeeding in juveniles of three cyprinid species. Env. Biol. Fish., 33 : 63-71.

Wells R.M.G. \& Weber R.E., 1991. is there an optimal haematocrit for rainbow trout, Oncorhynchus mykiss (Walbaum)? An interpretation of recent data based on blood viscosity measurements. J. Fish Biol., 38 : 5365.

Wilson R.P. \& Poe W.E., 1985. Relationship of whole-body and egg essential amino acid patterns to amino acid requirement patterns in Channel Cattish, lctalurus punctatus. Comp. Biocem. Physiol., 80B : 385-388.

Witters H.E., Van Puymbroeck S., Van Den Sande I. \& Vanderborgth O.L.J., 1990. Haematological disturbances and osmotic shifts in rainbow trout, Oncorhynchus mykiss (Walbaum) under acid and aluminium exposure. $J$. Comp. Physiol., 160B : 563-571.

Zeitoun I.H., Ullrey D.E. \& Tack P.I., 1974. Effects of water salinity and dietary protein levels on total serum protein and hematocrit of rainbow trout (Salmo gairdneri) fingerlings. J. Fish. Res. Board Can., 31: 1133-1134. 